Journal of Educational

and Psychological Sciences

Volume (5), Issue (37): 30 Oct 2021

P: 20 - 38

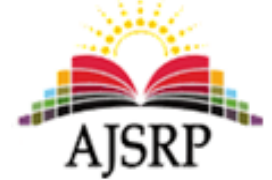

ISSN: 2522-3399
مجلة العلوم

التربوية والنفسية

المجلد (5)، العدد (37): 30 أكتوبر 2021 م

ص: 20 - 38

\title{
The Degree of Availability of Critical Thinking Skills among Arabic Language Teachers in Directorates Education in Karak Governorate, Jordan, from their Point of View
}

\author{
Sudgeh Awad Falaah Tarawneh \\ Quality and Accountability Unit || Ministry of Education || Jordan
}

\begin{abstract}
The current study aimed at identify the degree of availability of critical thinking skills among Arabic language teachers in the education directorates in Karak Governorate, Jordan, from their point of view, and to reveal the differences in that according to the variables of gender, academic qualification and the number of years of experience. and the researcher prepared a questionnaire consisting of (48) items distributed on (7) skills, namely: (analysis, induction, interpretation, conclusion, Calendar), and the indications for their validity and reliability were verified. Where a stratified random sample of (193) teachers was chosen from among the teachers of the Arabic language in the directorates of education in the governorate of Karak, The study found that the degree of availability of critical thinking skills among Arabic language teachers from their point of view was medium, with an arithmetic mean (3.42) and The skill of "deduction" came first, with an arithmetic average of (3.73), And with a high degree, while the "evaluation" skill came in the last place, with an arithmetic average of (2.93), and a medium degree. It also indicated that there are no statistically significant differences at the level of significance $(\alpha \leq 0.05)$ in the degree of availability of thinking skills. The critic among Arabic language teachers is attributed to gender, while it was found that there are statistically significant differences attributable to academic qualification and in favor of higher qualification (postgraduate studies), and the existence of statistically significant differences due to years of experience and in favor of those with higher experience.
\end{abstract}

Keywords: critical thinking skills among Arabic language teachers.

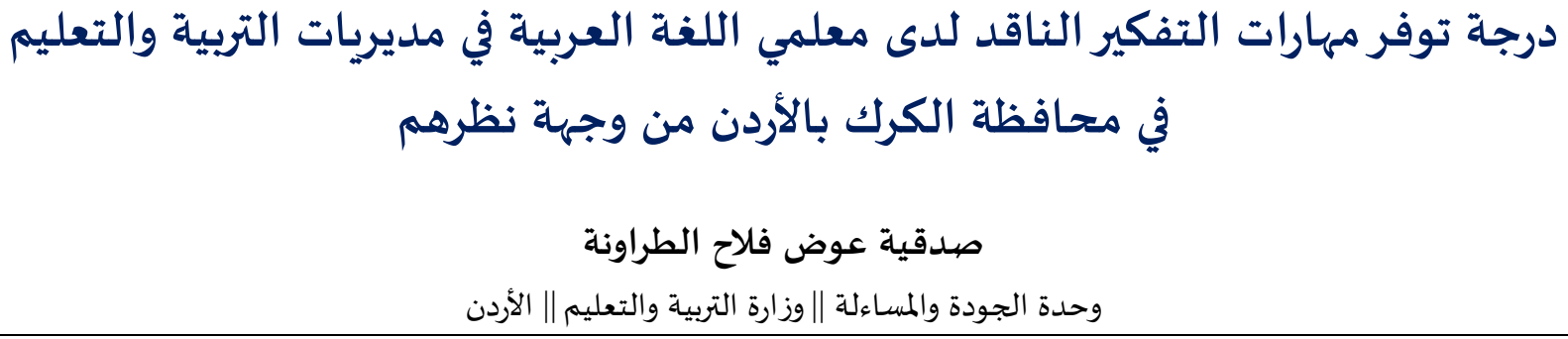

المستخلص: هدفت الدراسة الحالية التعرف على درجة توفر مهارات التفكير الناقد لدى معلمي اللغة العربية في مديريات التربية والتعليم في محافظة الكرك بالأردن من وجهة نظرهم، والكشف عن الفروق في ذلك تبعاً لمتغيرات الجنس والمؤهل العلمي وعدد سنوات الخبرة، ولتحقيق أهداف الدراسة تم الاعتماد على المنهج الوضفي التحليلي، وقامت الباحثة بإعداد استبانة تكونت من من (48) فقرة

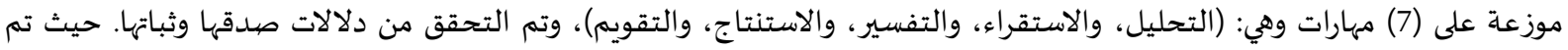

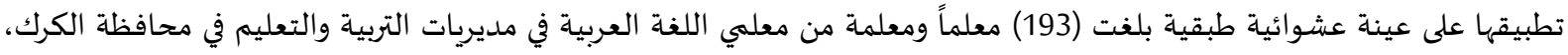

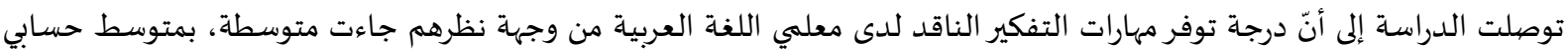

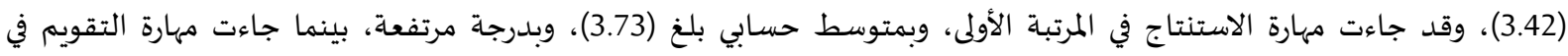


المرتبة الأخيرة وبمتوسط حسابي بلغ (2.93) وبدرجة متوسطة، كما أشارت إلى عدم وجود فروق ذات دلالة احصائية عند مستوى

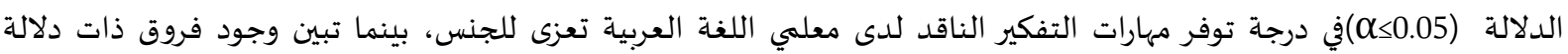
احصائية تعزى للمؤهل العلمي ولصالح المؤهل الاعلى (دراسات عليا)، ووجود فروق ذات ذات دلاتلة الحاتيات احصائية تعزى لسنوات الخبرة ولصالح ذوي الخبرة الأعلى.

الكلمات المفتاحية: مهارات التفكير الناقد، معلمي اللغة العربية، الأردن.

مقدمة.

تعد مهارات التفكير الناقد من الأمور المهمة والتي تأتي نتيجة للتطورات وانسجاماً مع تغيرات العصر، وما

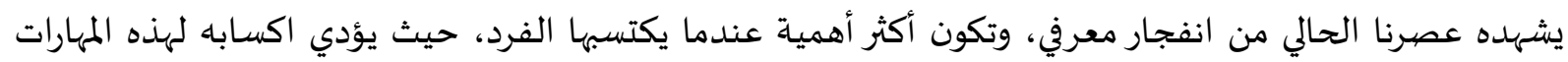

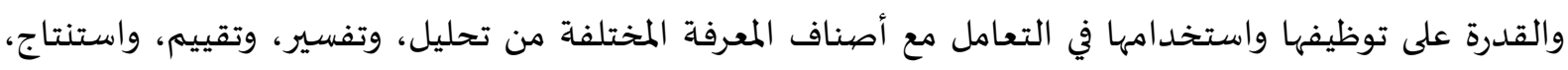

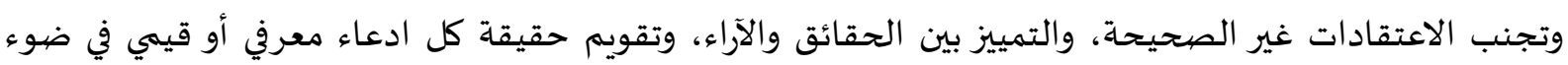

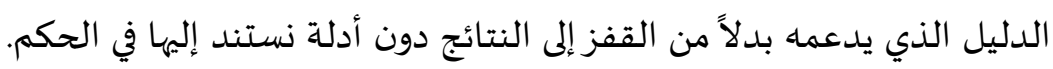

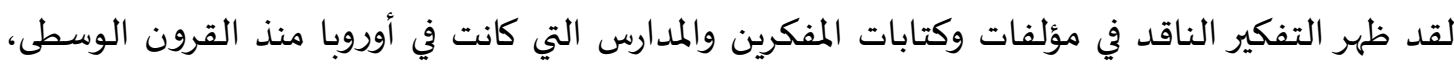

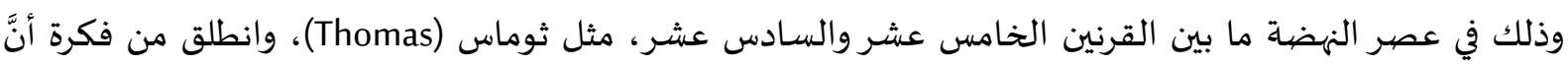

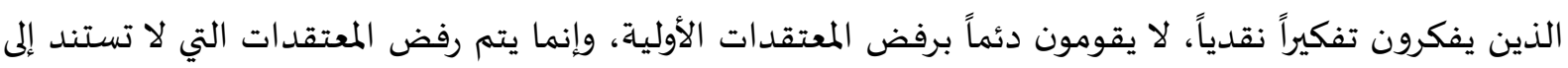

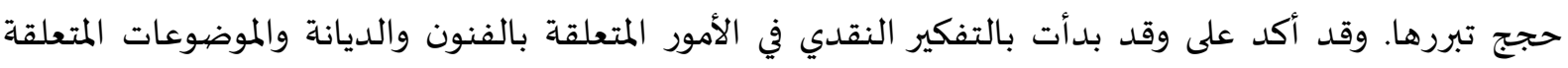

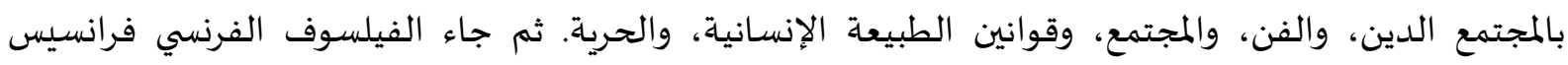

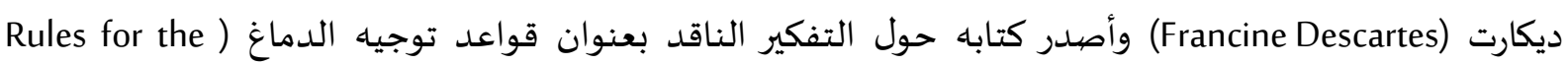
(Direction of the Mind)، حيث دوّن فيه منهجها في التفكير في صورة قواعد هي مضمون هذون هذا الكتاب، وتناول فيه

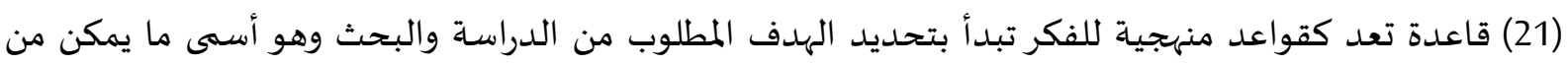
الأهداف وهو إدراك ما هو مستطاع من الحقيقة المطلقة ذات الوحدة والكمال، ثم يتناول بمنطقية الكيفية العامة

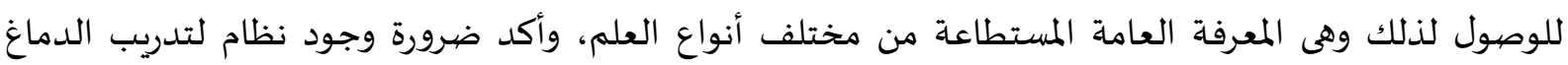

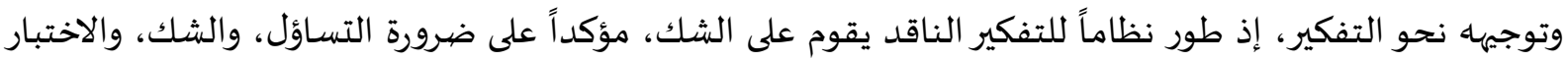

(Paule, Elder \& Bartell, 1997)

لقد كانت محاولة جون ديوي (John Dewey) في أواخر الثلاثينات من القرن الماضي من أولى المحاولات التي تطرقت لتعريف التفكير الناقد حيث عرّفه بأنه: تفكير انعكاسي (Reflective Thinking) يرتبط بالنشاط ونس والمثثابرة، وهو

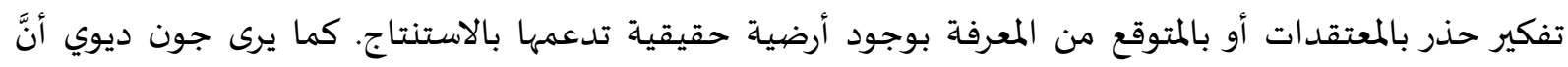

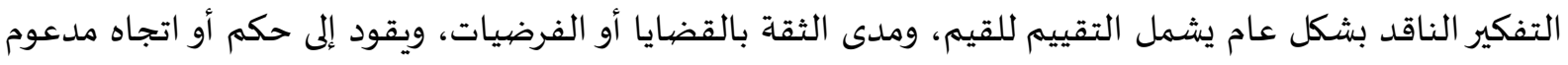

بالعمل (Fisher, 2001:2).

ويعد التفكير الناقد واحداً من أنماط التفكير التي تسهم في تكوين الفرد ليكون أكثر انفتاحاً، لكي يستقبل كل ما هو جديد، من أجل مواجهة المستقبل وتقبل أفكاره والتكيف معاه، ومواجهة ما يفرضاه من تحديات وما ئنيا يثيره

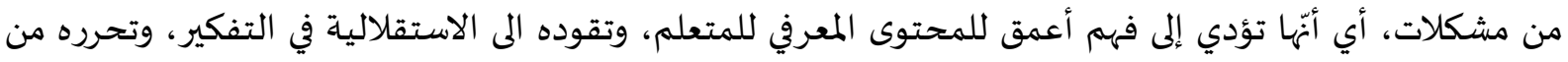

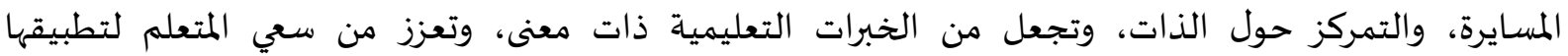

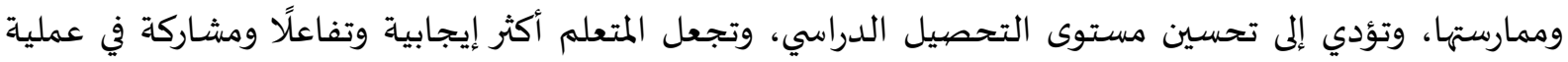


التعلم، وتعزز من قدرة المتعلم في حل مشكلاته، واتخاذ القرارات المناسبة بشأنها، وتزيد من ثقة المتعلم بنفسها، وترفع من مستوى تقديره لذاته (رزوقي وعبد الكريم، 2015). وقد تطرق جروان (2016) إلى أهمية التفكير الناقد بالاستناد لما أشارت إليه معظم الدراسات التهريد التجريبية، في

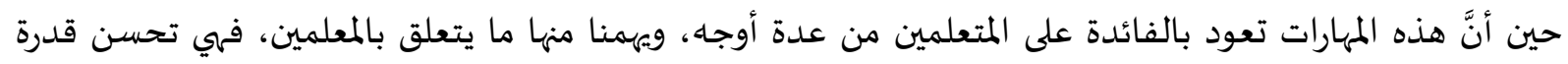

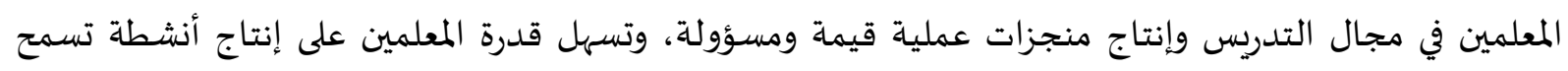

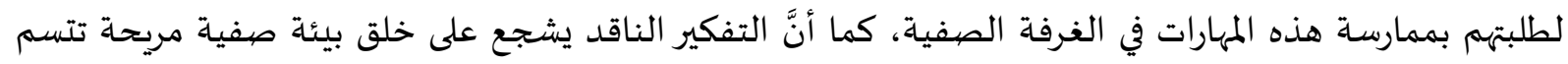
بحرية الحوار والمناقشة الهادفة. ولكي يكون المعلم ناجحا في عمله، فعليه أدوار كثيرة، ومن هذه الأدوار، تعليم الطلبة كيفية اكتساب المنادهاب

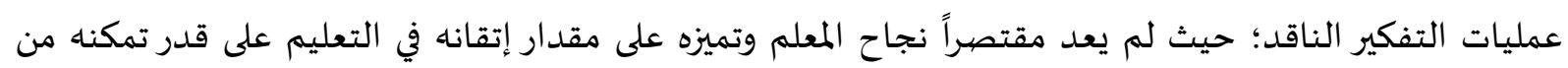

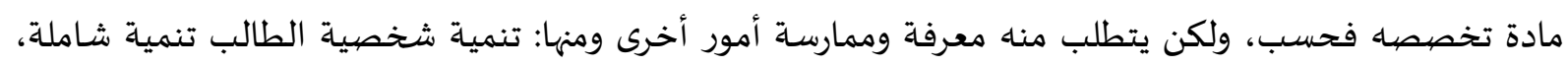

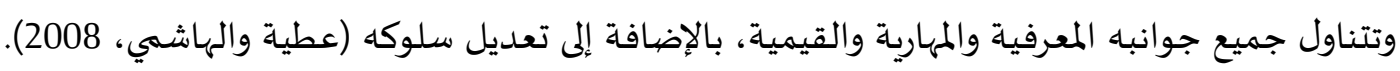

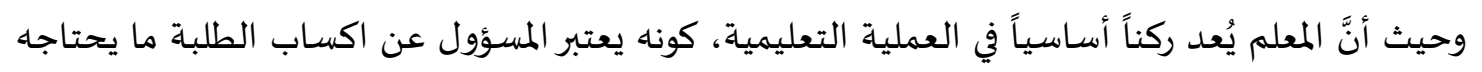

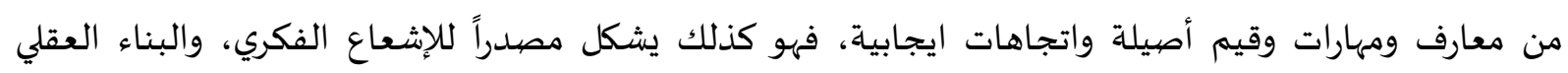

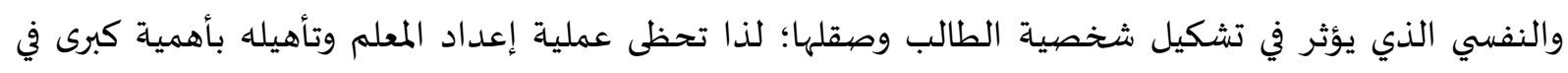

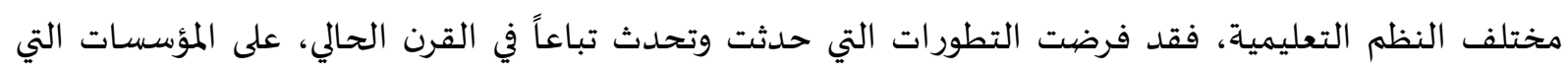

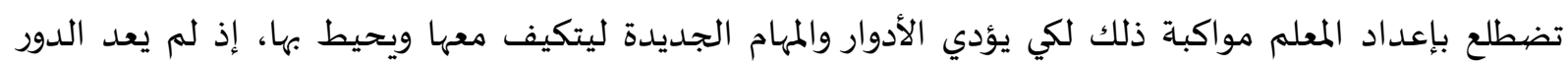

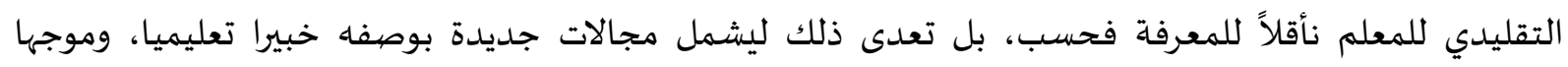

لطلابه، ومرشدا، وباحثا ومحللا تربويا، فضلا عن كونه قادرا على مواكبة للتطورات، ومتمرسا في مادته التعليمية.

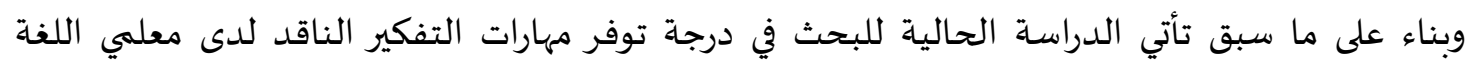

العربية في مديريات التربية والتعليم في محافظة الكرك بالأردن من وجهائ نظرهم.

مشكلة الدراسـة

إنَّ مهارات التفكير الناقد تُعد مجالاً استراتيجياً من مجالات المنظومة التعليمية، كما أنها تشكل المكون

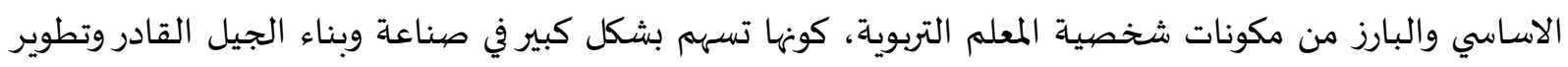
المجتمع. وقد أشـارت بعض الدراسة إلى وجود ضعف لدى المعلمين بشكل عام في امتلاك مهارات التفكير الناقد

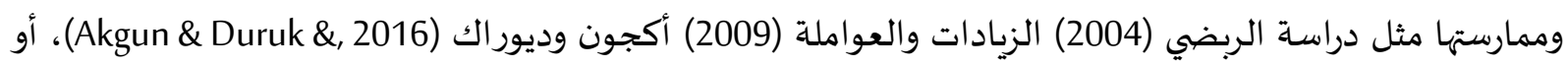
في بعض مهارته مثل دراسة الحسامي (2012) والتي أشارت إلى عدم استخدام المعلمين لاستراتيجيتي التفسير وتقويم الحجج. ولعل مشكلة الدراسة تتبلور في الحاجة الماسة لامتلاك الفرد لمهارات التفكير عموماً ومهارات التفكير الناقد

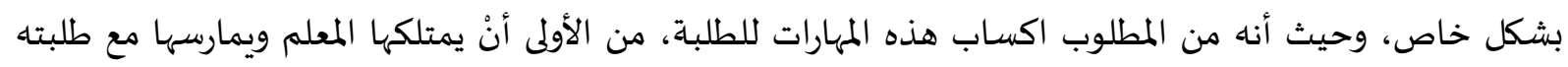

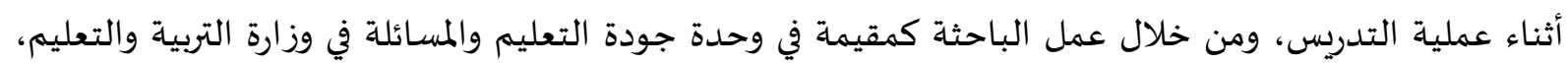

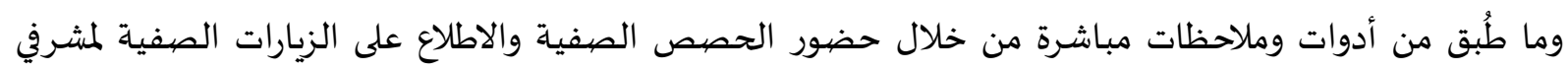

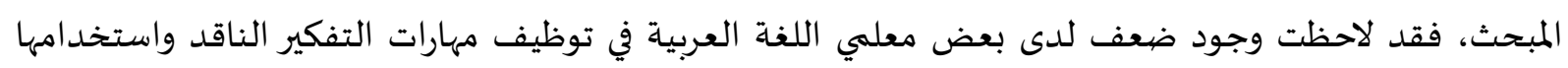

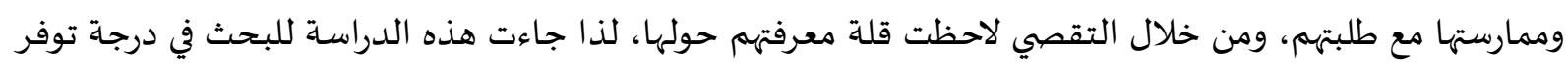


مهارات التفكير الناقد لدى معلمي مبحث اللغة العربية في مديريات التربية والتعليم في محافظة الكرك من وجها نظرهم، وذلك من خلال الاجابة عن الأسئلة التالية:

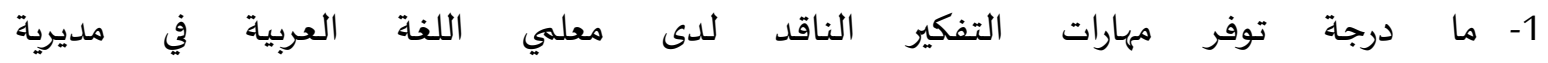
التربية والتعليم في محافظة الكرك بالأردن من وجهاة نظرهم؟ توفئ

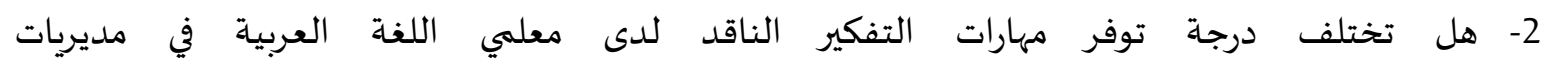
التربية والتعليم في محافظة الكرك بالأردن من وجهة نظرهم باختلاف متغيرات الجنس والمؤهل العلمي وعدد

$$
\text { سنوات الخبرة؟ ونئ }
$$$$
\text { أهداف الدراسة }
$$

تهدف الدراسة الحالية إلى:

1- التعرف على درجة توفر مهارات التفكير الناقد لدى معلمي اللغة العربية في مديريات التربية والتعليم في محافظة الكرك بالأردن من وجهة نظرهم. 2- الكشف عن الفروق في ذلك تبعاً لمتغيرات الجنس والمؤهل العلمي وعدد سنونة فئوات الخبرة.

يمكن تلخيص أهمية الدراسة من الناحية العملية بالنقاط الآتية: 1- قد يساعد استقصاء مدى امتلاك معلمي اللغة العربية لمهارات التفكير الناقد القائمين على إعداد وتأهيل

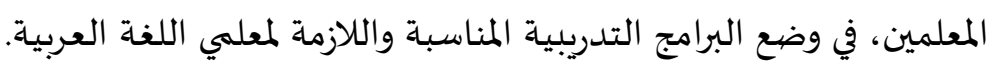
2- يعد هذه البحث من الأبحاث القليلة التي حاولت تقصي مستوى مهارات التفكير الناقد لدى معلمي اللغة

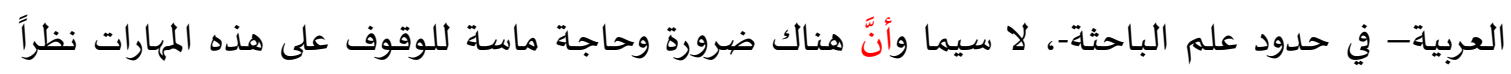

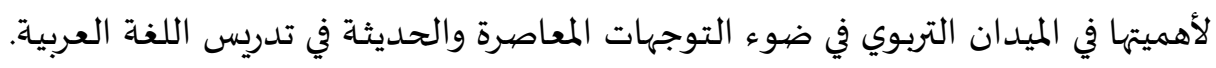

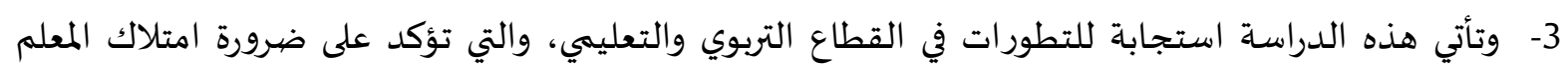

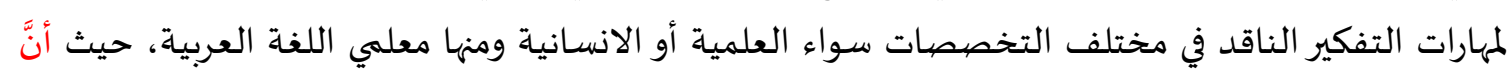

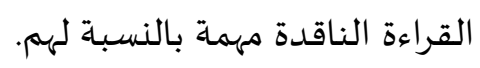
أما الأهمية النظرية فتبرز في أنه قد يستفيد من نتائجها طلبة الدراسات العليا والباحثين، عند القيام بإجراء دراسات مماثلة.

اقتصرت هذه الدراسة على الحدود التالية:

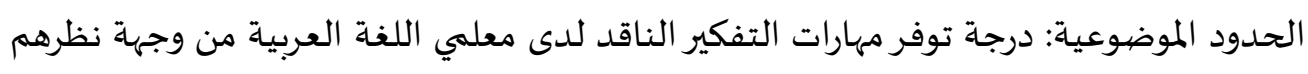
الحدود البشرية: معلمي اللغة العربية. الحدود المكانية: مدارس مديريات التربية والتعليم في محافظة الكرك في المملكة الأردنية الهاشمية.

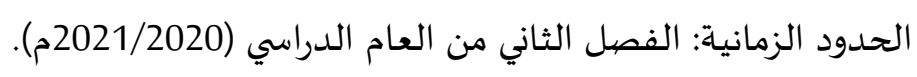


- - التفكير الناقد: ويعرفه موري وباركر (Moore \& parker, 2009:3) بأنه عبارة عن "الحكم الحذر والمتأني لما ينبغي

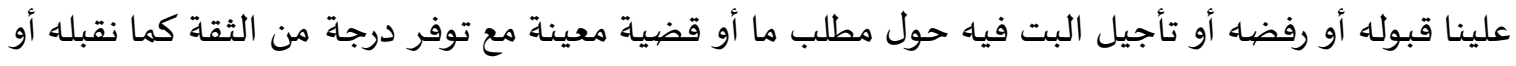
نرفضهاه"، ويعرف إجرائياً بالدرجة التي حصل عليها الطالب في مقياس التفكير الناقد المستخدم في هذه الدراسـة ويعرف إنيس (Ennis, 1992) التفكير الناقد على أنها تفكير تأملي عقلاني (Reflective Reasonable Thinking)

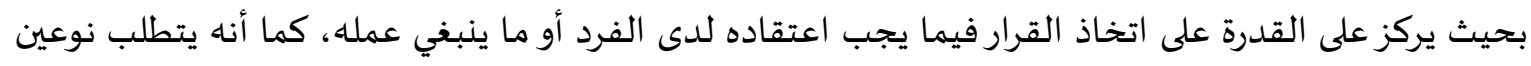

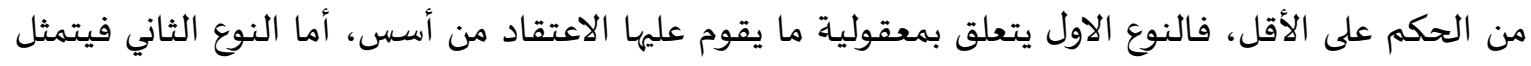

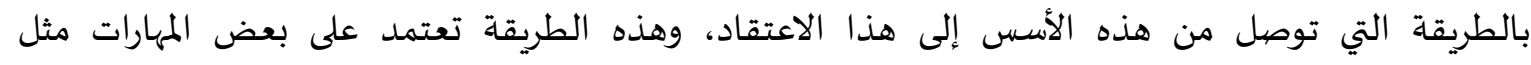

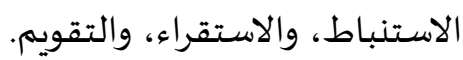
كما أنه يعني قدرة الفرد على التفاوض الذكي مع نفسـاءه ومع الآخرين في كثير من القرارات في الحياة اليومية ضمن المحيط الذي يعيش به (Frazier, 1997). وتعرفه هالبرن (Halpern, 1998) بأنه نوع من أنواع التفكير الهادف المعتمد على الاستدلال والاحتمالات الممكنة، واتخاذ القرارات المناسبة لحل مشكلات محددة، وانجاز مهام وواجبات معينة.

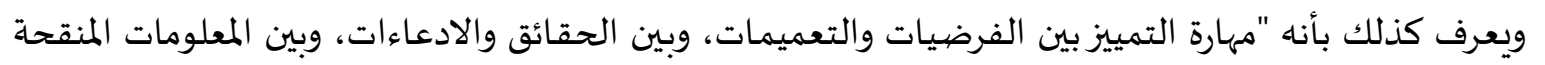

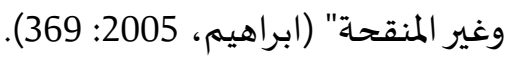
كما يعرف بأنه العملية العقلية التي تشتمل على مجموعة من مهارات التّفكير، والتي من الممكن استخدامها

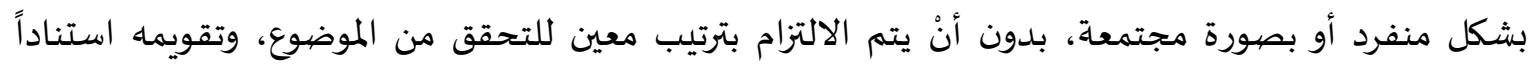

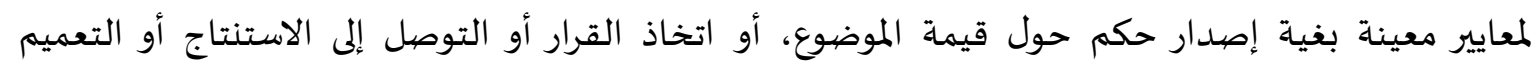
(قطامي، 2004).

واورد كريستوفر (Christopher, 1998) التعريف التالي للتفكير الناقد بأنه الإدراك فوق المعرفي وذلك بغية

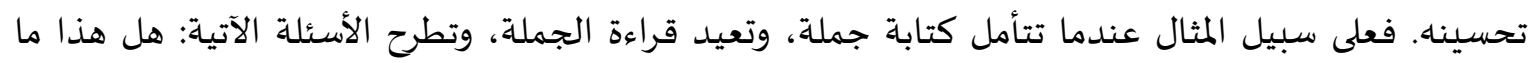
أريد قوله؟ هل هذا يشكل النقطة التي أرغب عملها؟ هل تتطلب هذه الجملة المزيد من التوضيح؟ هل هل تحتاج إلى إلى طرح أمثلة؟.

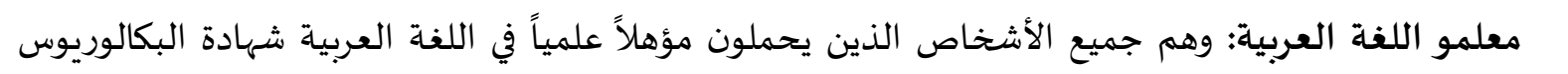

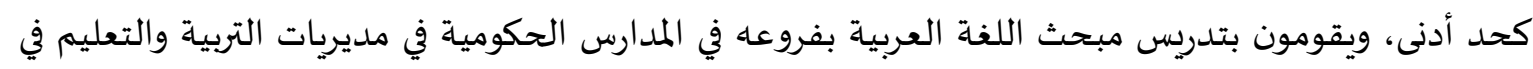
محافظة الكرك للعام الدراسي 2021/2020م

2. الإطار النظري والدراسـات السـابقة. أولاًَ- الإطار النظري. مهارات التفكير الناقد: وقد صنف باير (Beyer, 1997) التفكير الناقد إلى عشر مهارات هي (التمييز بين الحقائق والادعاءات،

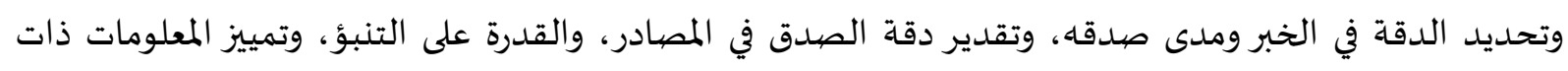


العلاقة من غيرها، وتعريف الفرضيات غير الواضحة، وفهم الأخبار والمناقشات الغامضة والمتداخلة، ومعرفة

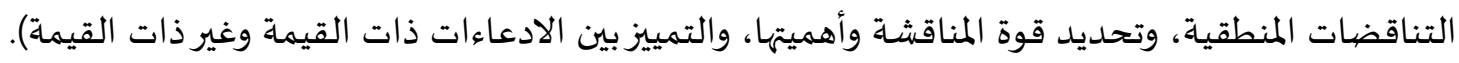

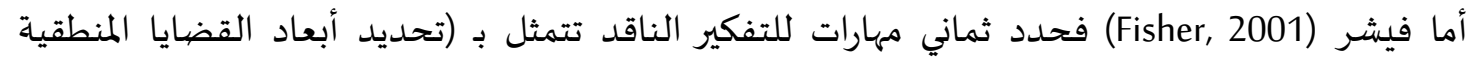
وعناصرها وخصوصاً الأسباب والنتائج، وتقييم الافتراضات وتحديدها بدقة، وإيضاح الأفكار والآراء والأفكار

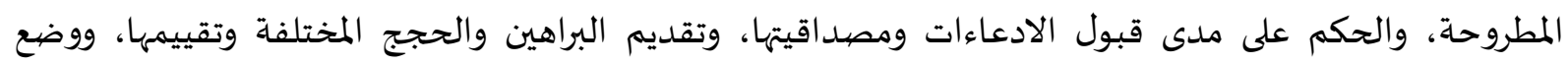
التفسيرات المنطقية المناسبة، واتخاذ القرارات المناسبة وإخضاعها للتحليل والتقويم، وتقديم الاستدلالات المنطقية). وقدم واطسون وجليسر (Watson \& Glaser, 1980) إنموذجاً للمهارات التي يتضمنها التفكير الناقد، وهي:

$$
\text { تقدييز الفرضير الدقة في مصدر ما. }
$$

Facione \& Facione, ويشتمل التفكير الناقد على خمس مهارات (النبهان، 2010، مرعي ونوفل، 2007؛

1- مهارة التحليل Analysis Skill: يقصد بالتحليل تحديد العلاقات ذات الدلالات المقصودة والفعلية بين

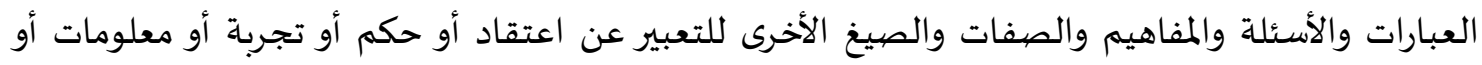

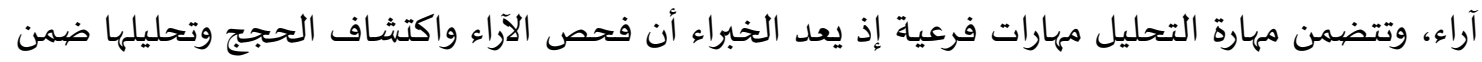

$$
\text { مهارات التحليل الفرعياة. }
$$

2- مهارة الاستقراء Induction Skill: يقصيد بهذه المهارة أنَّ صحة النتائج مرتبطة بصديلة المقدمات، ومن الأمثلة

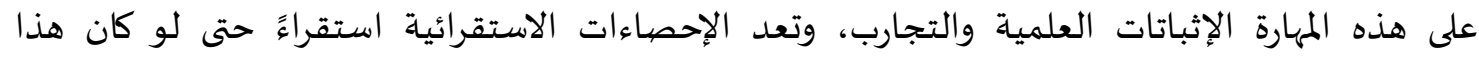

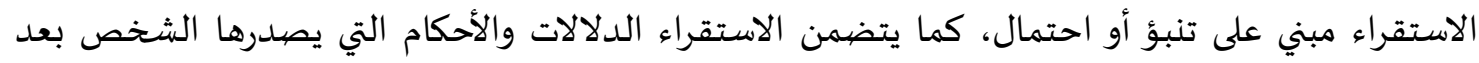

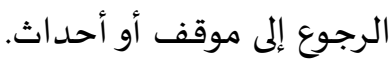
3- مهارة التفسير أو الاستدلال Inference Skill: تشير هذه المهارة إلى ممارسة مجموعة من العمليات التي تعتمد

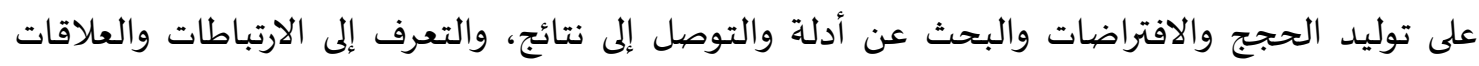
السببية. 4- مهارة الاستنتاج Deductive Skill: تشير هذه المهارة إلى تحديد وتوفير العناصر اللازمة لاستخلاص النتائج

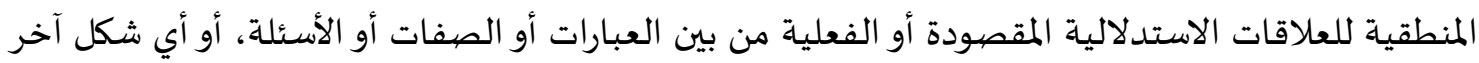

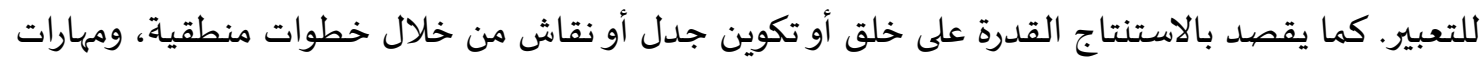

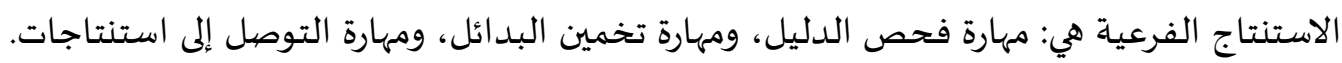

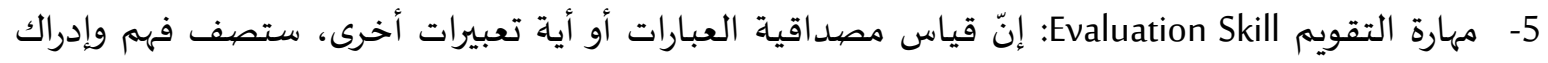

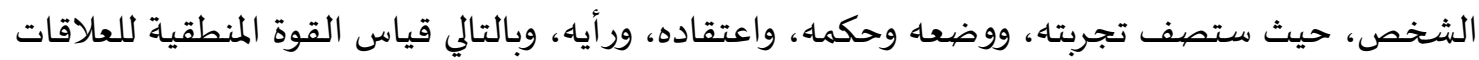

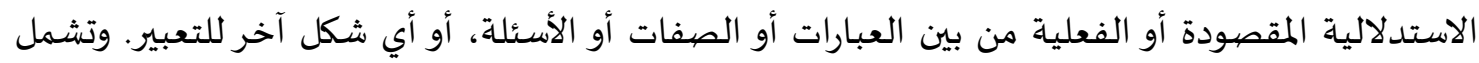

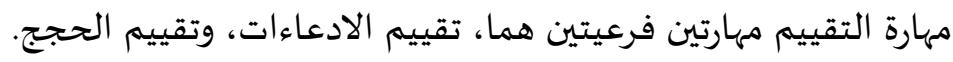


ثانياً - الدراسـات السابقة:

- أجرت الربضي (2004) دراسة هدفت التعرف على درجة معرفة معلمي الدراسات الاجتماعية في المرحلة الثانوية

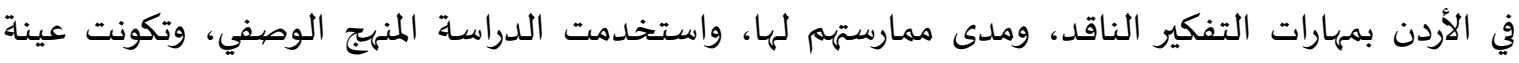

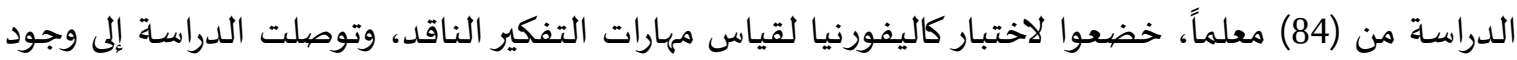

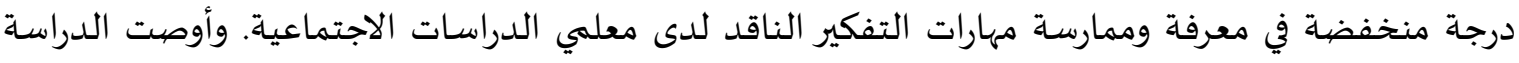

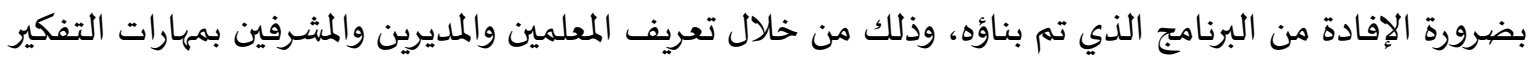
الناقد، وعلى استخدام البرنامج.

وأجرى مرعي ونوفل (2007) دراسة هدفت إلى الكشف عن مستوى امتلاك طلبة كلية العلوم التربوية الجامعية (الأونروا) لمهارات التفكير الناقد، واستخدم المنهج الوصفي التحليلي، وتكونت عينة الدراسة من من (510) طالباً

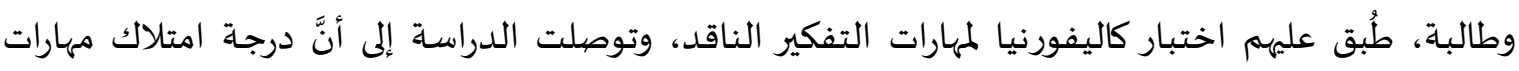

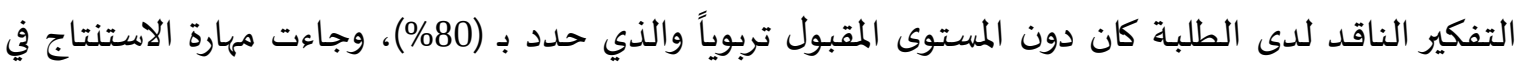
المرتبة الأخيرة، كما أظهرت النتائج وجود فرق في مستوى مهارات التفكير الناقد تعزى لمتغير الجنس ولصالح

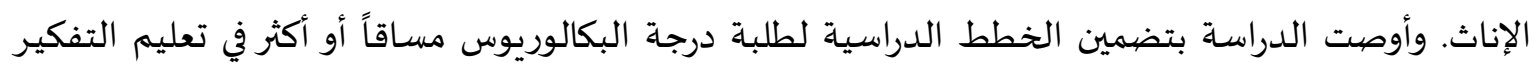
بشكل عام، أو التفكير الناقد بشكل خاص، والاهتمام في التعليم الجامعي بمهارات الاستنتاج والتقييم والتحليل بخاصية وبقية مهارات التفكير بعامة. - وأجرى الزيادات والعواملة (2009) دراسة هدفت إلى الكشف عن مدى امتلاك معلمي مبحث التاريخ في مديرية

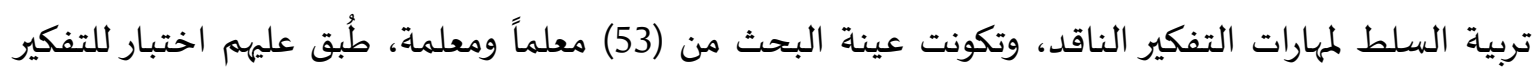

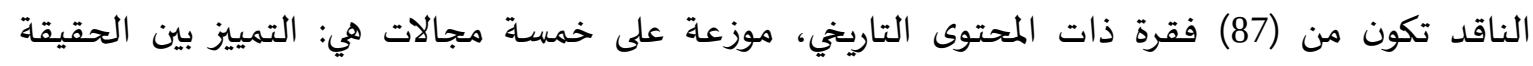

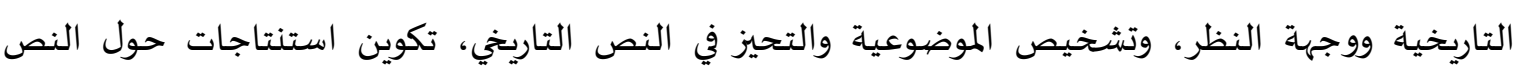

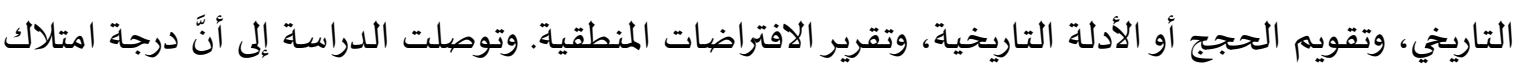

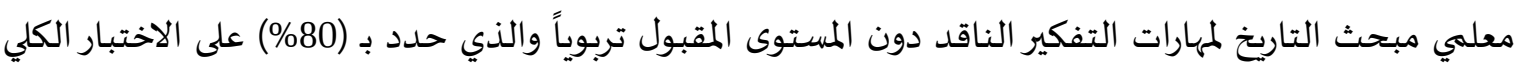

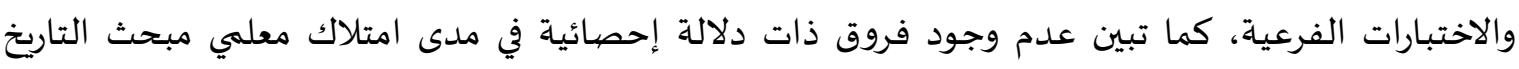

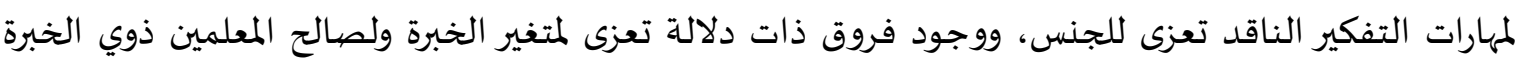

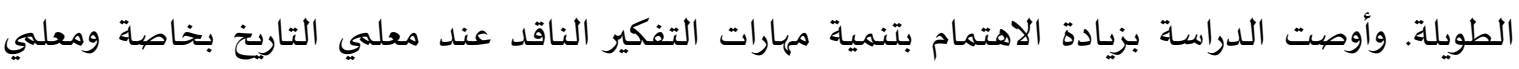
الدراسات الاجتماعية بعامة، وتضمين برامج إعداد معلمي التاريخ مساقات تستهدف تدريههم على استخدام طرائق التفكير الناقد واستراتيجياته، تدريب معلمي التاريخ على امتلاك مهاراته بـات التفكير الناقد. كما أجرى النبهاني (2010) دراسة هدفت الكشف عن مستوى مهارات التفكير الناقد لدى طلبة كلية العلوم

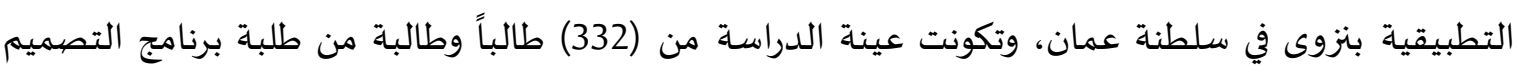

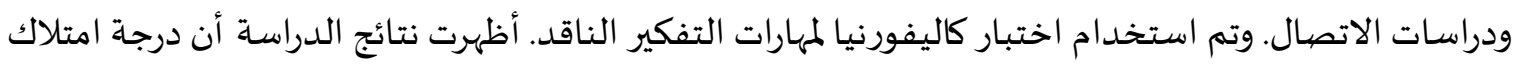

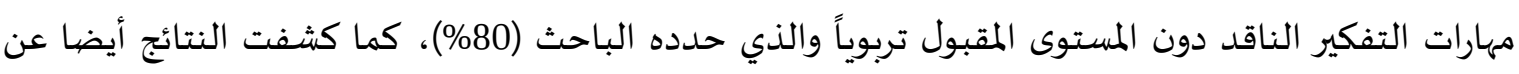

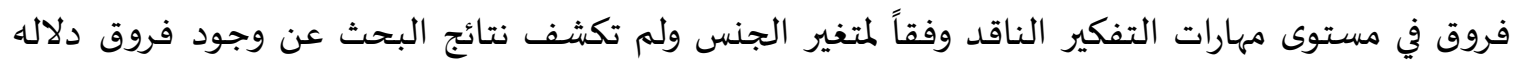

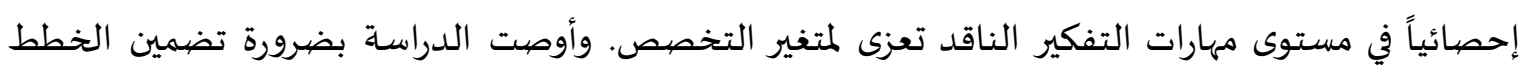

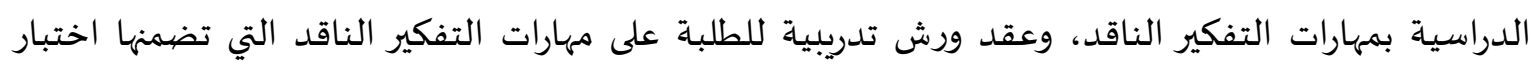
كاليفورنيا. 
- كما أجرى كل من الهاشمي والعزاوي والحلاق (2010) دراسـة هدفت الى التعرف على درجة تمكن معلمي اللغة

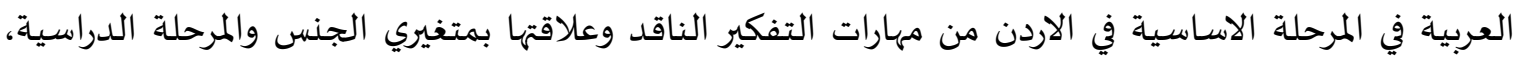
وتكونت عينة الدراسة من (50) معلم ومعلمة في مديريات التربية في محافظة عمان، طُبق علئ عليهم اختبار

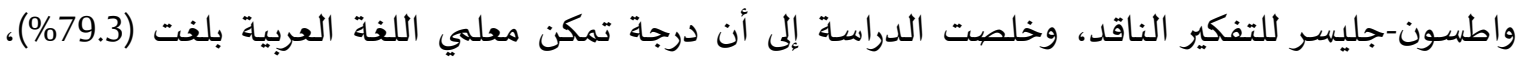

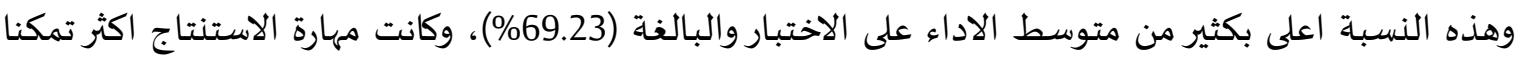

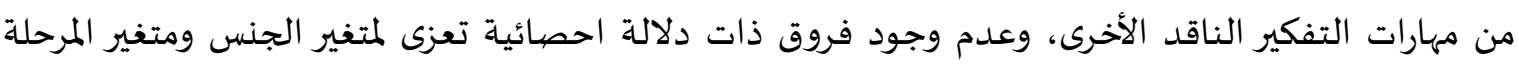

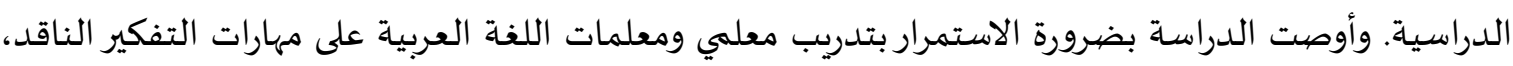
والحفاظ على ما لديهم من مهارات.

وهدفت دراسة كنيك (Kanik, 2010) إلى استكشاف تصورات المعلمين حول التفكير الناقد وممارستا لتنمية

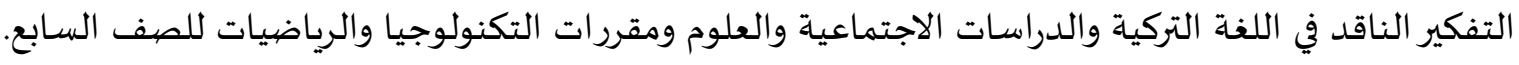

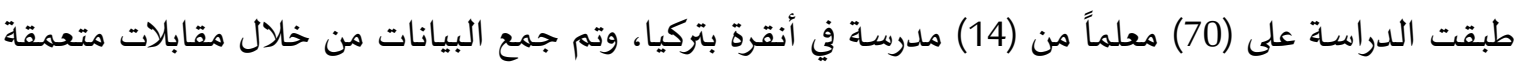

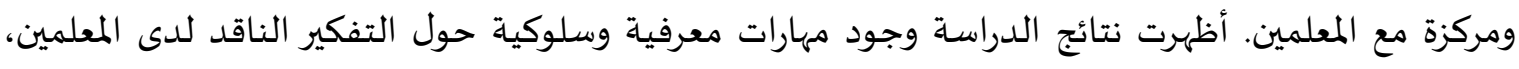

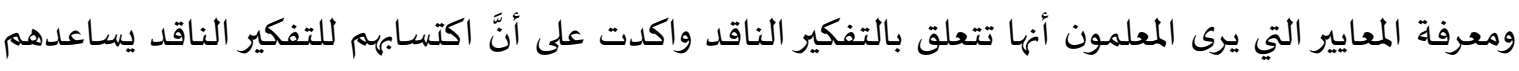

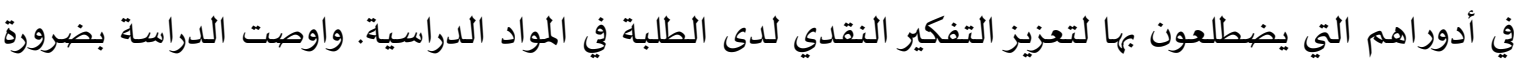
تعزيز التفكير النقدي لدى المعلمين للقيام بأدوارهم في عملية التدريس.

وأجرى الحسامي (2012) دراسة هدفت إلى التعرف على الاستراتيجيات التفكير الناقد التي يستخدمها معلمي

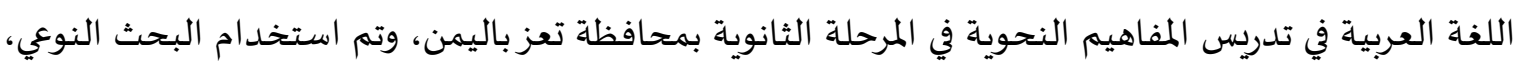

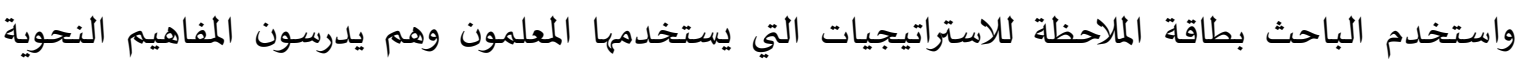

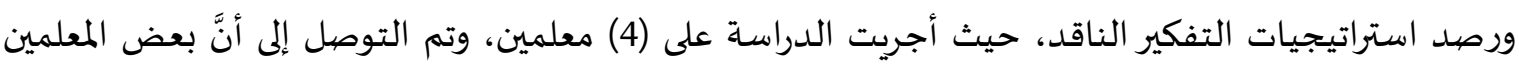

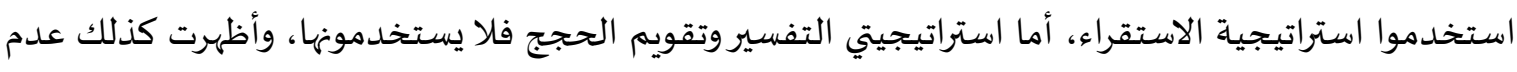

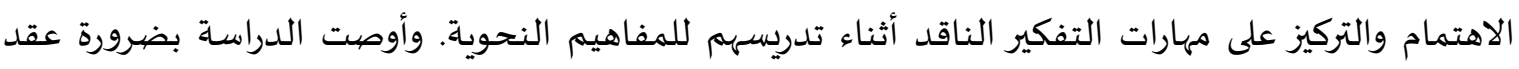
ورش تدريبية لمعلمي اللغة العربية في توظيف استراتيجيات التفكير الناقد في تدريس المفاهيم النحوية، والتركيز على استراتيجيتي التفسير وتقويم الحجب.

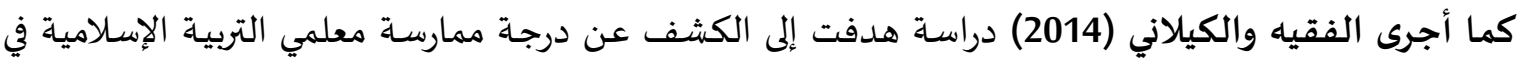

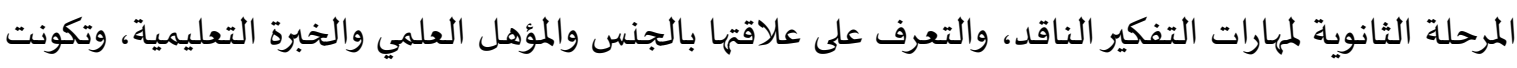

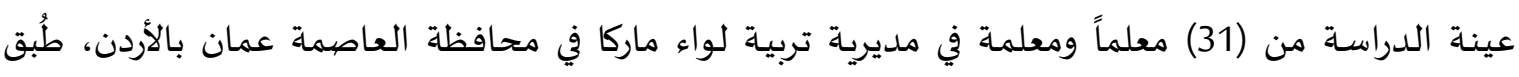

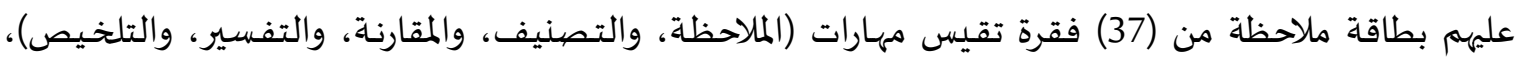

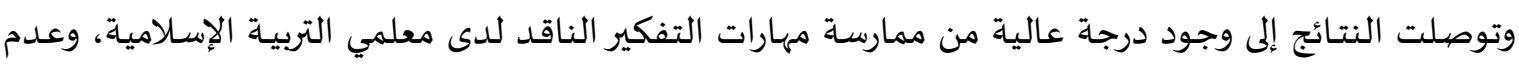

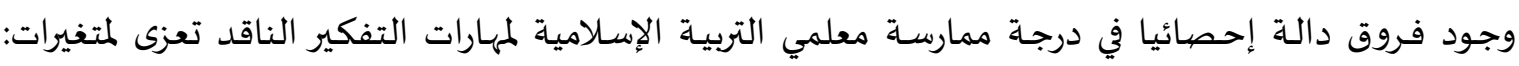

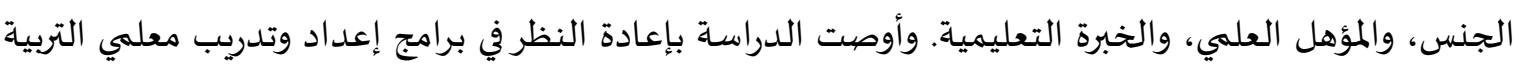

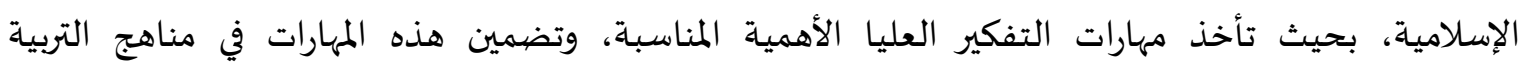
الإسلامية. كما هدفت دراسة الحراحشة (2015) إلى التعرف على مدى امتلاك معلمي العلوم للمرحلة الأساسية العليا

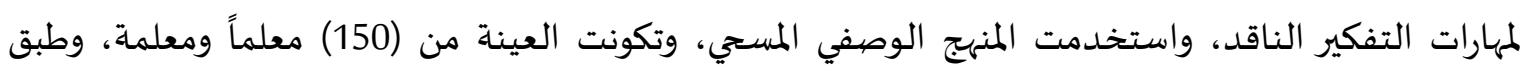
عليهم مقياس مهارات التفكير الناقد والذي يقيس مهارات (التحليل - الاستقراء - التفسير - الاستنتاج - التقويم)، 
وأظهرت النتائج أنَّ درجة امتلاك معلمي العلوم للمرحلة الأساسية العليا لمهارات التفكير الناقد من وجهة نظر

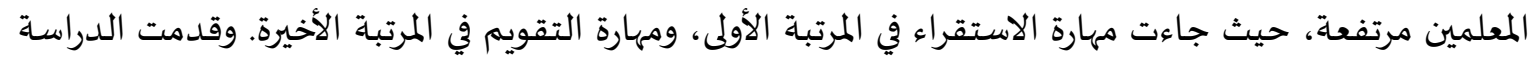

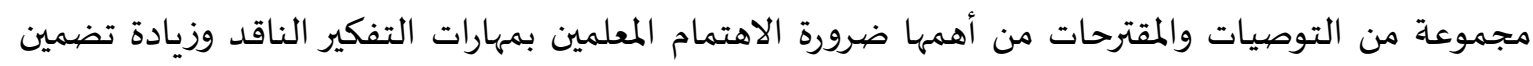
كتب العلوم على مهارات التفكير الناقد.

وهدفت دراسة أكجون وديوراك (Akgun \& Duruk \&, 2016) التعرف على مستوى التفكير الناقد لدى معلهي العلوم (قبل الانخراط في التدريس) في سياق العوامل الشخصية والاجتماعية بتركيا، وتم استخدام المنهج

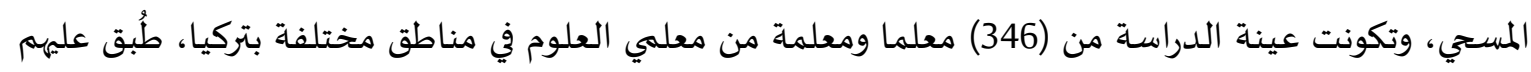

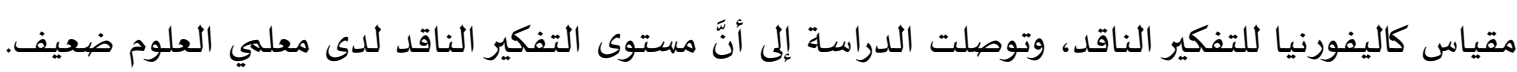

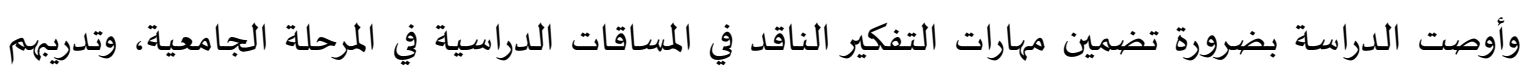
عليها قبل الانخراط في عملية التدريس. كما أجرى حمادنة والشواهين (2017) دراسة هدفت إلى التعرف على درجة امتلاك مهارات التفكير الناقد لدى الديه

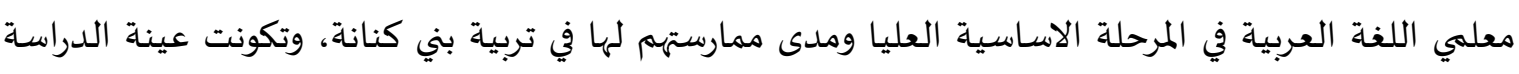

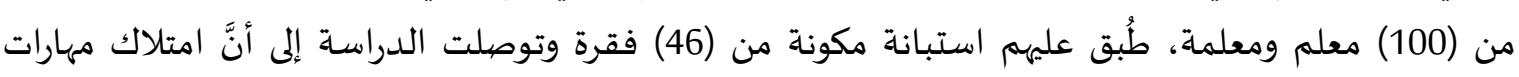

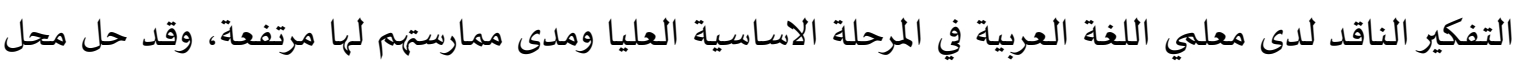

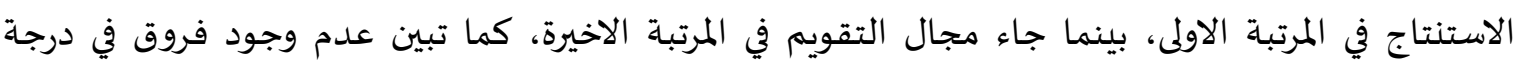

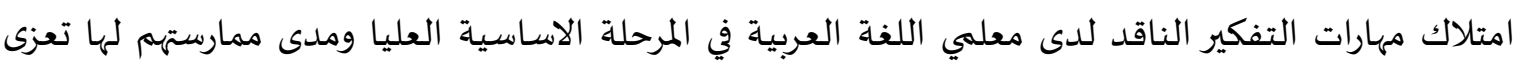

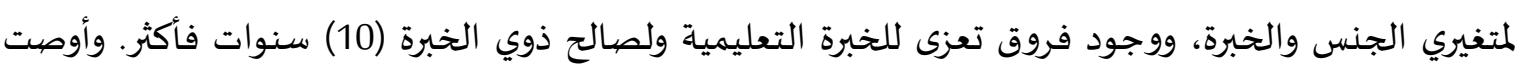

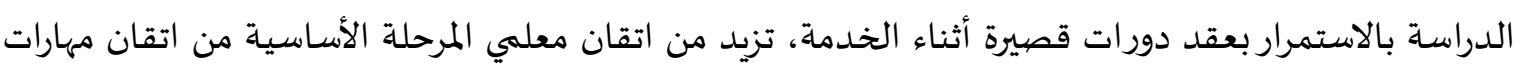

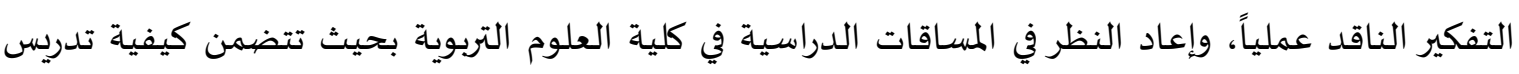
مهارات التفكير الناقد.

كما أجرت الوادعي (2017) دراسـة هدفت إلى استقصاء أثر استخدام دورة التعلم الخماسي فيي تنمية مستوى

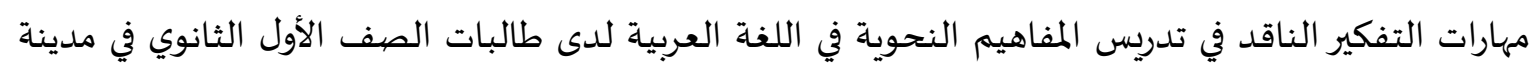

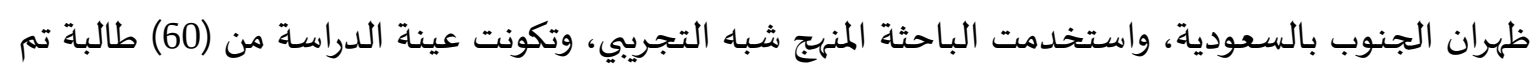

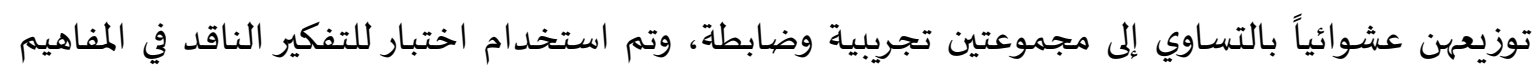

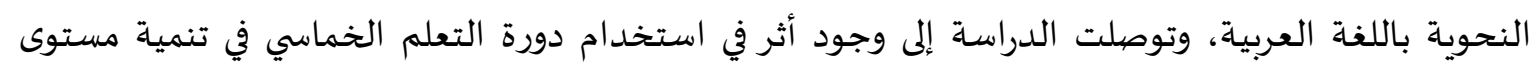

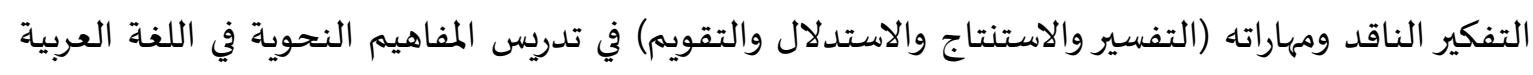

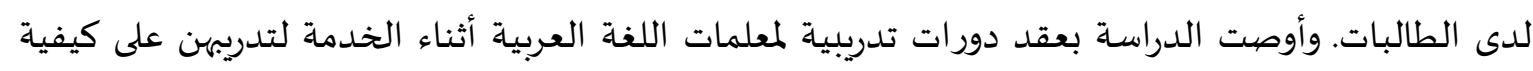
استخدام دورة التعلم الخماسية (s'5E) في تدريس المفاهيم النحوية باللغة العربية للمراحل التعليمية المختلفة. وأجرى الحميري (2018) دراسة التعرف إلى درجة ممارسة معلمي العلوم لمهارات التفكير الناقد وعلاقته بمهارات

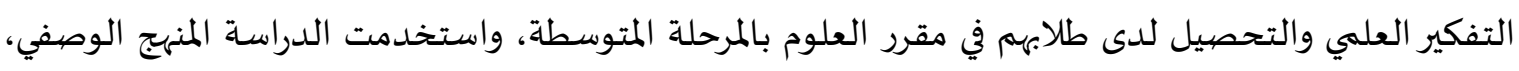

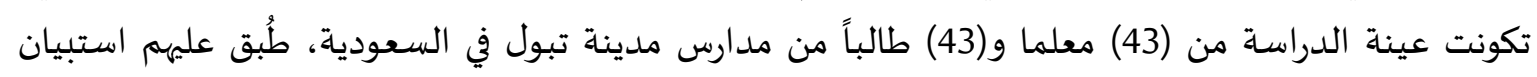

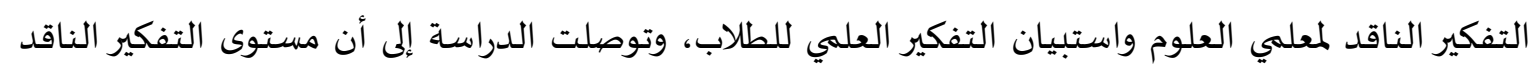

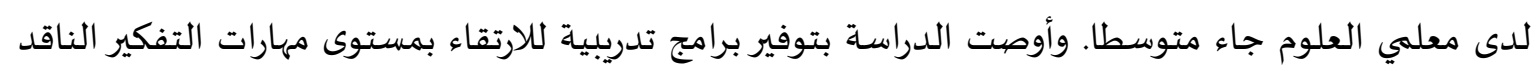

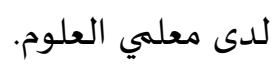


وهدفت دراسة الكركي والمحادين (2019). التعرف إلى مستوى التفكير الناقد لدى طلبة جامعة مؤتة وعلاقته

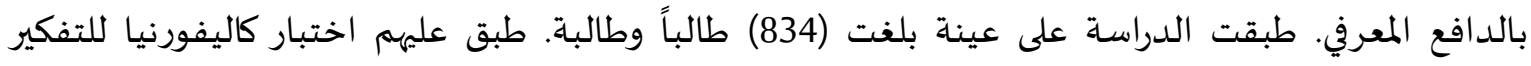

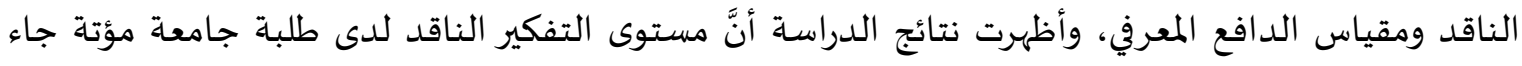

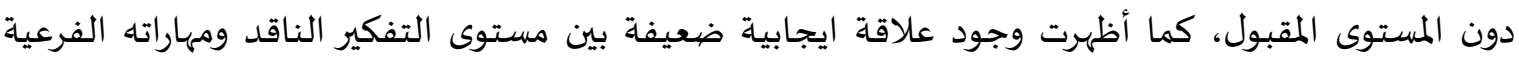

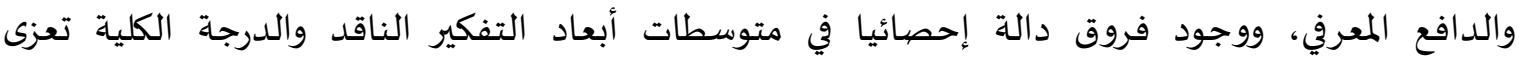

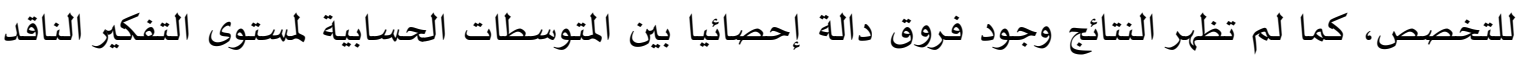

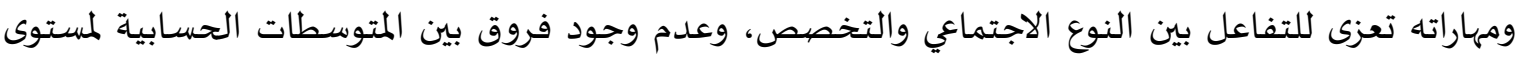

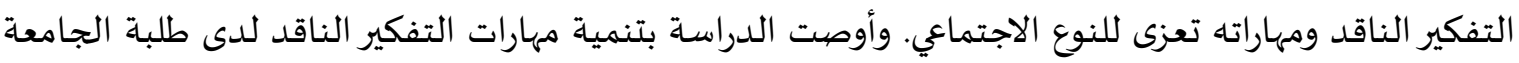
وخاصة طلبة الدراسات الإنسانية من خلال تضمين الخطط الدراسية لمساقات وموضوعات تستهدف تعلئه تعليم التفكير بشكل عام، أو التفكير الناقد بشكل خاص.

التعقيب على الدراسات السابقة من حيث المنهج فغالبية الدراسة استخدمت المنهج الوصفي وبالاعتماد على العينة، ولكنها تتباين في الادوات فمنها ما استخدم المقاييس والاختبارات كقياس كاليفورنيا وواطسون وجليسر ومنها ما استخدم الاستبانة كما هو في

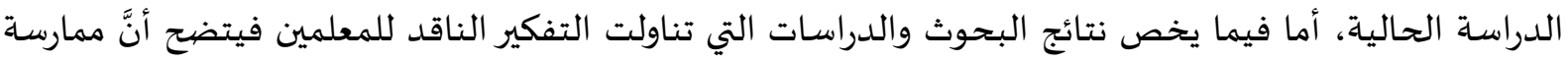

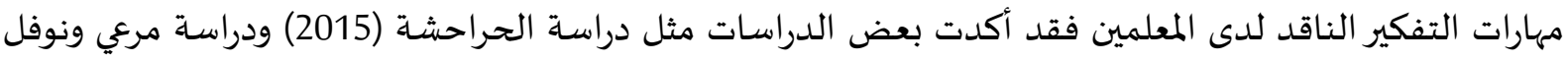

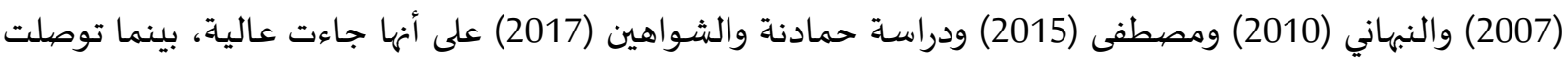
دراسة أخرى مثل دراسة الزيادات والعواملة (2009) أكجون وديوراك (2007) (Akgun \& Duruk \&, 2016) إلى أنها جاءت اتهات

منخفضية.

3. منهج الدراسـة وإجراءاتها.

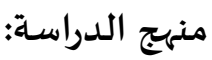
استخدم الباحث المنهج الوصفي باعتباره المنهج العلمي الأكثر مناسبة لطبيعة الدراسة الحالية.

مجتمع الدراسـة

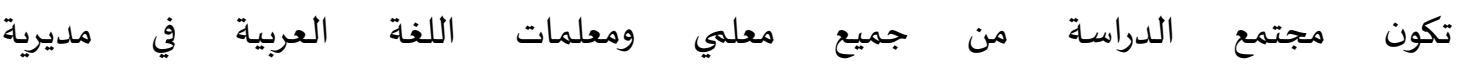

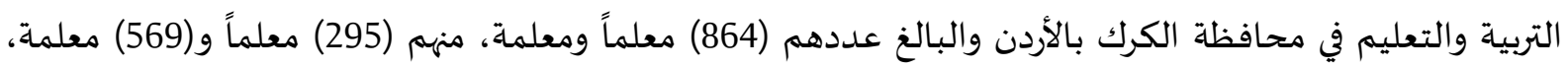
وذلك وفقاً للإحصاءات الرسمية لوزارة التربية والتعليم للعام (2021/2020م).

عينة الدراسـة

تكونت عينة الدراسة من (193) معلمة ومعلمة اختيرت بالطريقة العشوائية الطبقية، طبقية حسب

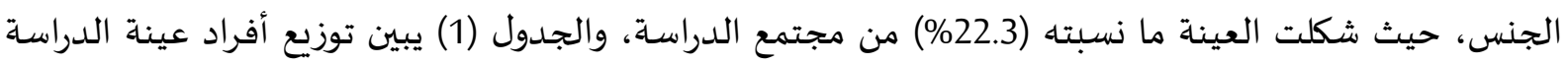
حسب الجنس والمؤهل العلمي وسنوات الخبرة: 
جدول (1) يبين توزيع أفراد الدراسة حسب الجنس والمؤهل العلمي وعدد سنوات الخبرة

\begin{tabular}{|c|c|c|}
\hline العدد العد & الجنس & المتغير \\
\hline 86 & ذكر & \multirow{2}{*}{ الجنس } \\
\hline 107 & أنثى & \\
\hline 127 & بكالوريوس & \multirow{2}{*}{ المؤهل العلمي } \\
\hline 66 & دراسـات عليا & \\
\hline 57 & أقل من 5 سنوات & \multirow{3}{*}{ الخبرة } \\
\hline 74 & 5- 10 سنوات & \\
\hline 62 & 10 سنوات فأكثر & \\
\hline
\end{tabular}

أداة الدراسة

لجمع البيانات المتعلقة بالدراسة قامت الباحثة بتطوير استبانة التفكير الناقد بالاستناد إلى الادب النظري والدراسات السابقة ذات الصلة، وقد تضمنت الاستبانة (46) فقرة موزعة على (5) مهارات وهي: (مهارة التحليل وتضم (9) فقرات، ومهارة الاستقراء وتضم (7) فقرات، ومهارة التفسير وتضم (8) فقرات، ومهارة الاستنتاج وتضيم

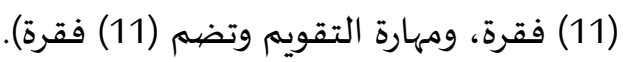

الصيدق الظاهري لأداة الدراسة تم التحقق من صدق الاستبانة من خلال عرضها على مجموعة من حملة الدكتوراه في الجامعات الأردنية

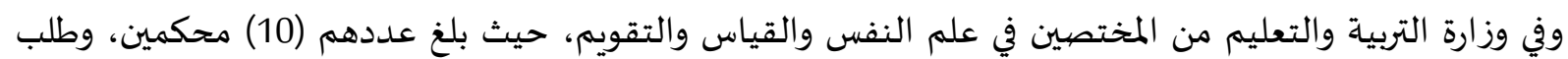
إليهم بيان مدى صلاحية الفقرات ومناسبتها اللغوية وتقديم أي ملاحظات من حيث الإضافة أو الحذف أو أو التعديل.

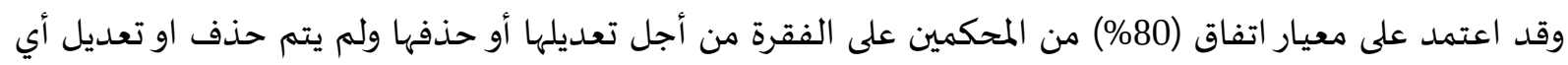

صدق البناء (الاتساق) الداخلي لأداة الدراسة تم التحقق من صدق الاستبانة باستخدام صداق الاتساق الداخلي بحساب معامل ارتباط بيرسون بين

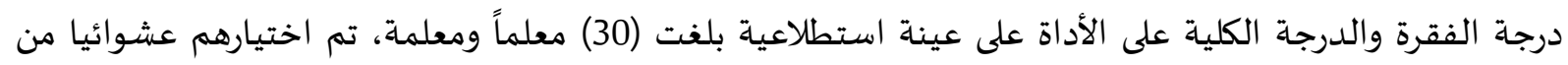

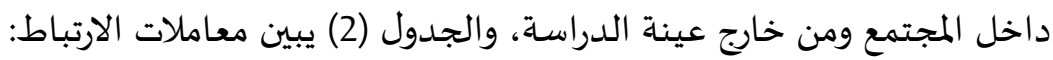

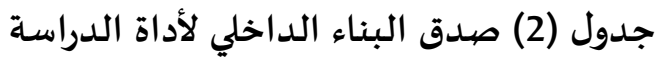

\begin{tabular}{|c|c|c|c|c|c|c|c|c|c|}
\hline الارتباط معامل & رقفم & الارتباط & الفقرة & الارتباط & الفقرة & معامل الارتباط & الفقرة & الارتباط & رقمق الفقرة \\
\hline \multicolumn{2}{|c|}{ التقويم } & \multicolumn{2}{|c|}{ الاستنتاج } & \multicolumn{2}{|c|}{ التفسير } & \multicolumn{2}{|c|}{ الاستقراء } & \multicolumn{2}{|c|}{ التحليل } \\
\hline $.512^{* *}$ & 36 & $.561^{* *}$ & 25 & $.479^{* *}$ & 17 & $.600^{* *}$ & 10 & $.517^{* *}$ & 1 \\
\hline $.640^{* *}$ & 37 & $.427^{*}$ & 26 & $.512^{* *}$ & 18 & $.398^{*}$ & 11 & $.436^{*}$ & 2 \\
\hline $.402^{*}$ & 38 & $.515^{* *}$ & 27 & $.434^{*}$ & 19 & $.597^{* *}$ & 12 & $.512^{* *}$ & 3 \\
\hline $.449^{*}$ & 39 & $.514^{* *}$ & 28 & $.785^{* *}$ & 20 & $.636^{* *}$ & 13 & $.640^{* *}$ & 4 \\
\hline $.627^{* *}$ & 40 & $.374^{*}$ & 29 & $.584^{* *}$ & 21 & $.407^{*}$ & 14 & $.402^{*}$ & 5 \\
\hline $.517^{* *}$ & 41 & $.507^{* *}$ & 30 & $.408^{*}$ & 22 & $.459^{*}$ & 15 & $.449^{*}$ & 6 \\
\hline
\end{tabular}


المجلة العربية للطوم ونشر الأبحاث ـ مجلة العلوم التربوية والنفسية ـ المجلد الخامس ـ العدد السابع والثلاثون ـ أكتوبر 2021م

\begin{tabular}{|c|c|c|c|c|c|c|c|c|c|}
\hline معامل الارتباط & الفقرة & معامل الارتباط & الفقرة & معامل الارتباط & الفقرة & معامل الارتباط & الفقرة & معامل الارتباط & الفقرة \\
\hline $.614^{* *}$ & 42 & $.488^{* *}$ & 31 & $.580^{* *}$ & 23 & $.420^{*}$ & 16 & $.627^{* *}$ & 7 \\
\hline $.516^{* *}$ & 43 & $.516^{* *}$ & 32 & $.611^{* *}$ & 24 & & & $.517^{* *}$ & 8 \\
\hline $.645^{* *}$ & 44 & $.494^{* *}$ & 33 & & & & & & 9 \\
\hline $.532^{* *}$ & 45 & $.517^{* *}$ & 34 & & & & & & \\
\hline $.637^{* *}$ & 46 & $.436^{*}$ & 35 & & & & & & \\
\hline
\end{tabular}

يتبين من الجدول (2) بأنه تحقق للاستبانة مؤشرات صدق بناء داخلي جيدة، حيث تراوحت معاملات

الارتباط بين (0.374-0.645).

ثبات أداة الدراسة

تم التحقق من دلالات ثبات أداة الدراسة باستخدام معادلة كرونباخ ألفا للاتساق الداخلي على ذات العينة الاستطلاعية (ن=30)، ويبين الجدول (3) معاملات ثبات المقياس: جدول (3) معاملات ثبات أداة الدراسة (3) معات

\begin{tabular}{|c|c|c|}
\hline كرونباخ ألفا & عدد الفقرات & المهارة \\
\hline 0.85 & 9 & التحليل \\
\hline 0.82 & 7 & التفسير \\
\hline 0.84 & 8 & الاستقراء \\
\hline 0.88 & 11 & الاستنتاج \\
\hline 0.87 & 11 & التقويم \\
\hline 0.93 & 46 & الكلي \\
\hline
\end{tabular}

يلاحظ من الجدول (3) أن معامل ثبات كرونباخ ألفا للكلي بلغ (0.93)، وللمهارات تراوحت معاملات الثبات

بين (0.88-0.82).

تصحيح ادة الدراسة

تتم الاستجابة على الاستبانة وفقاً لسلم ليكرت الخماسي (عالية جداً، عالية، متوسطة، قليلة، قليلة جدا) وتعطى الدرجات (5، 4، 3، 2، 1) على الترتيب، وتكون أعلى درجة يمكن الحصول عليها (230) وأدنى درجة (46)، وتم

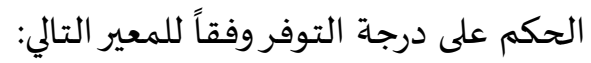

$$
\text { بدربة بدرجة متلدمة مرتلة }
$$$$
\text { الفترة }
$$$$
\text { أقل من } 2.34
$$$$
\text { منن } 2.34 \text { إلى أقل من } 3.68
$$$$
3.68 \text { فأكثر }
$$

إجراءات تطبيق الدراسة: 1- اعتماد أداة الدراسة (استبانة التفكير الناقد) التي تم استخدامها ومدى مناسبتها للتطبيق والتأكد من دلالات صددقها وثباتها. 2- اختيار عينة الدراسة من المدارس. 
3- الحصول على أعداد معلمي المدارس في محافظة الكرك وأسماء المدارس وعناوينها وهواتف المدرسة للتواص (5) 4- تطبيق الاستبانة على أفراد الدراسة بتوزيعها يدوياً على جميع معلمي اللغة العربية في مدارس العينة المختارة. 5- ادخال البيانات الى الحاسب وتحليلها باستخدام برمجية (SPSS, V16).

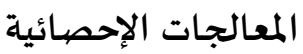

لالإجابة عن أسئلة الدراسة تم استخدام ما يلي:

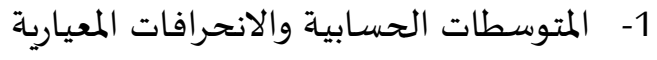

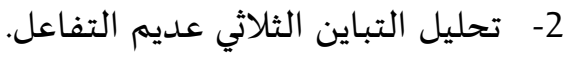

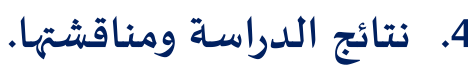

• السؤال الأول: ما درجة توفر مهارات التفكير الناقد لدى معلمي اللغة العربية في مديريات التربية والتعليم في

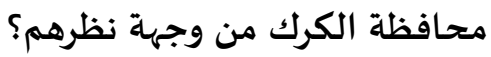

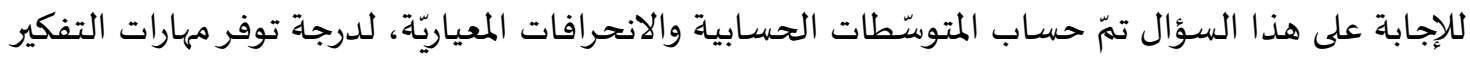

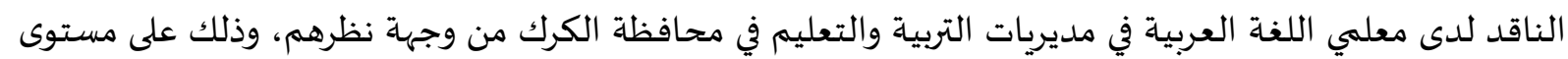
كل مجال والمجال الكلي والجدول (4) يوضح نتائج ذلك:

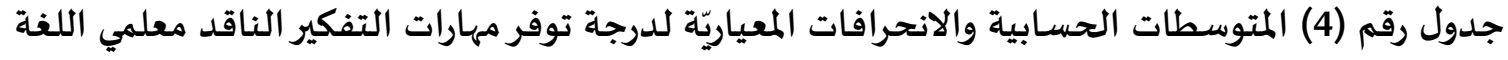

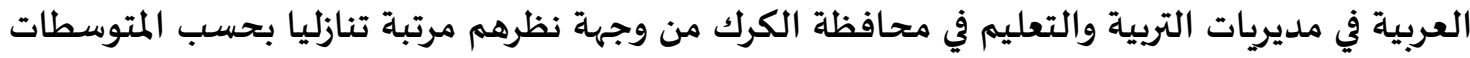

\begin{tabular}{|c|c|c|c|c|c|}
\hline الدرجة & الرتبة & الاتحراف المعياري & المتوسط الحسـابي & المهارة & $\hat{\imath}$ \\
\hline مرتفعة & 1 & .54 & 3.73 & الاستنتاج & 4 \\
\hline مرتفعة & 2 & .49 & 3.69 & الاستقراء & 3 \\
\hline متوسطة & 3 & .58 & 3.66 & التحليل & 1 \\
\hline متوسطة & 4 & .60 & 3.07 & التفسير & 2 \\
\hline متوسطة & 5 & .47 & 2.93 & التقويم & 5 \\
\hline متوسطة & -- & .45 & 3.42 & الكلي & \\
\hline
\end{tabular}

يبين الجدول رقم (4) أنّ درجة توفر مهارات التفكير الناقد لدى معلمي اللغة العربية في مديريات التربية

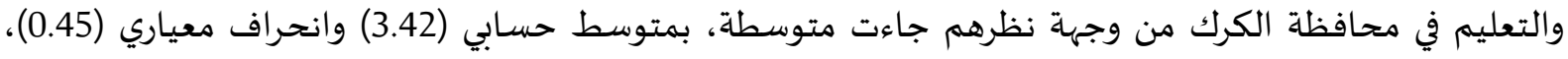

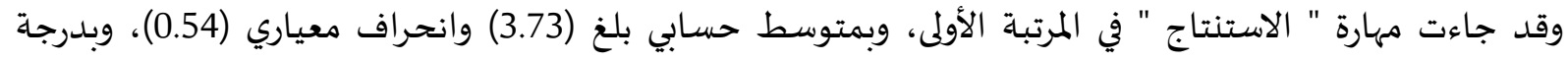
مرتفعة، بينما جاءت مهارة " التقويم " في المرتبة الأخيرة وبمتوسط حسابي بلغ الغاتئ (2.93) وانحراف معياري (0.47) وبدرجة متوسطة.

ويمكن تفسير هذه النتيجة يعود إلى قلة معرفة المعلمين بمهارات التفكير الناقد، وطرائق إكسابها للطلبة

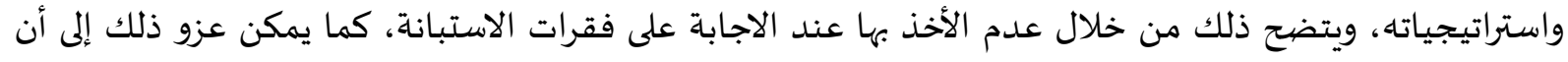

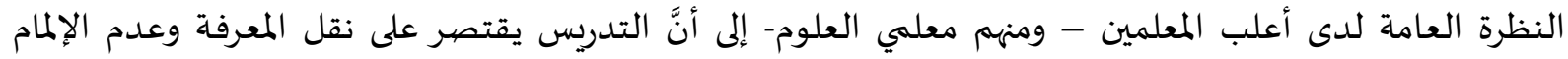


باستخدام طرائق واستراتيجيات التدريس التي تسـاعد على تحدي التفكير لدى الطلبة، بحيث يكون لديهم فهم أعمق

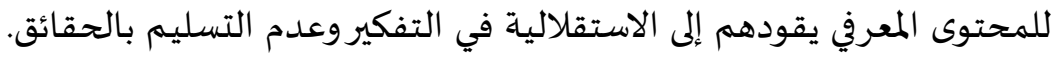

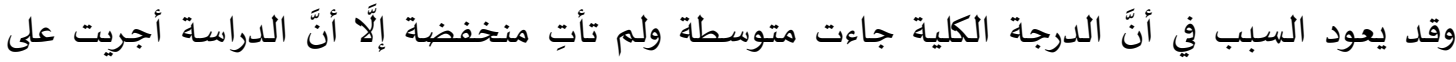
معلمي العلوم، والذين قد يميلون إلى توظيف التفكير العلمي المنطقي في تفكيرهم وتدريسهم، إضافة إلى ذلك فإنَّ إنَّ

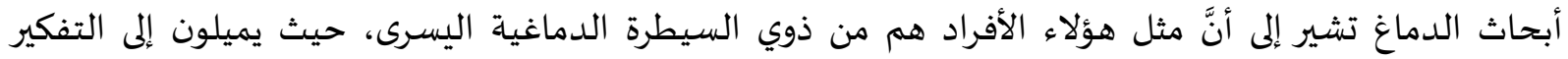
المنطقي التجريدي، وتفكير الخطوة تلو الخطوة، وإلى التفكير التقاربي، والدماغ الأيسر يمثل جوهر التهر التفكير التهير المنطقي، والتفكير المنطقي تفكير يستند إلى النقد.

وتفسير السبب في أنَّ مهارة الاستنتاج قد جاءت في المرتبة الأولى وبدرجة مرتفعة إلى أهها تتضمن مجموعة من العمليات كاستخلاص النتائج المنطقية من العلاقات، وخلق جدل أو نقاش بخطوات منطقية، وفحص الأدلة وتخمين البدائل، وكل هذه العمليات قد يمارسها المعلم في العديد من مواقف الحياة.

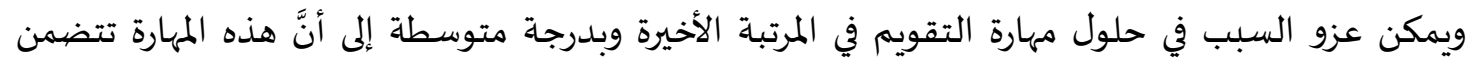
تقييم الادعاءات والحجج، وتتلخص صعوبتها في العمليات التي تشتمل عليها، وبالتالي قلة استخدام وممارسة المعلمين

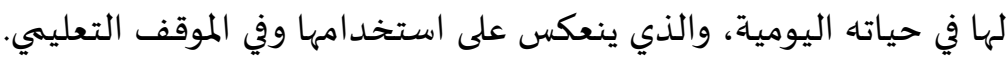

السؤال الثاني: هل تختلف درجة توفر مهارات التفكير الناقد لدى معلمي اللغة العربية في مديريات التربية والتعليم في محافظة الكرك من وجهة نظرهم باختلاف الجنس والمؤهل العلمي وسنوات الخبرة؟

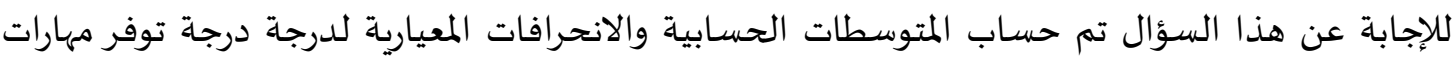
التفكير الناقد لدى معلمي اللغة العبية في مديريات التربية والتعليم في محافظة الكرك من وجهة نظرهم تبعا لمتغيرات (الجنس، المؤهل العلمي، سنوات الخبرة) والجدول (5) يبين ذلك: جدول (5) المتوسطات الحسابية والانحرافات المعيارية لدرجة توفر مهارات التفكير الناقد لدى لده معلمي اللغة العربية في مديريات التربية والتعليم في محافظة الكرك من وجهة نظرهم تبعا لمتغيرات (الجنس، المؤهل العلمي، سنوات الخبرة)

\begin{tabular}{|c|c|c|c|c|c|c|c|c|}
\hline ال اكلي & التقويم & الاستنتاج & التفسير & الاستقراء & التحليل & & فئة المتغير & المتغير \\
\hline 3.44 & 2.94 & 3.76 & 3.71 & 3.06 & 3.69 & المتوسط الحسابي & \multirow{2}{*}{ ذكر } & \multirow{4}{*}{ الجنس } \\
\hline .33 & .38 & .50 & .33 & .48 & .47 & الانحراف المعياري & & \\
\hline 3.40 & 2.93 & 3.70 & 3.67 & 3.08 & 3.63 & المتوسط الحسابي & \multirow{2}{*}{ أنثى } & \\
\hline .52 & .53 & .57 & .58 & .68 & .66 & الانحراف المعياري & & \\
\hline 3.35 & 2.88 & 3.66 & 3.64 & 2.98 & 3.59 & المتوسط الحسابي & \multirow{2}{*}{ بكالوريوس } & \multirow{4}{*}{ الملمي } \\
\hline .52 & .52 & .64 & .53 & .67 & .67 & الانحراف المعياري & & \\
\hline 3.54 & 3.03 & 3.85 & 3.79 & 3.25 & 3.78 & المتوسط الحسابي & \multirow{2}{*}{ دراسات عليا } & \\
\hline .19 & .33 & .21 & .36 & .37 & .32 & الانحراف المعياري & & \\
\hline 3.24 & 2.79 & 3.55 & 3.52 & 2.91 & 3.44 & المتوسط الحسابي & \multirow{2}{*}{ أقل من5سنوات } & \multirow{6}{*}{ سنوات الخبرة } \\
\hline .68 & .61 & .85 & .62 & .79 & .86 & الانحراف المعياري & & \\
\hline 3.45 & 2.92 & 3.75 & 3.75 & 3.11 & 3.71 & المتوسط الحسابي & \multirow{2}{*}{ من10سنوات } & \\
\hline .31 & .39 & .36 & .42 & .51 & .42 & الانحراف المعياري & & \\
\hline 3.54 & 3.08 & 3.87 & 3.77 & 3.18 & 3.80 & المتوسط الحسابي & \multirow{2}{*}{ 10سنوات فأكثر } & \\
\hline .22 & .36 & .18 & .379 & .44 & .34 & الانحراف المعياري & & \\
\hline
\end{tabular}


يتبين من الجدول (5) وجود فروق ظاهرية بين المتوسطات الحسابية في درجة توفر مهارات التفكير الناقد

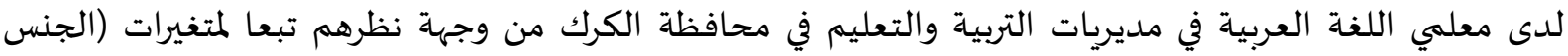
Three Way ( المؤهل العلمي، سنوات الخبرة)، ولمعرفة دلالة تلك الفروق تم استخدام تحليل التباين الثلاثي (ANOVA عديم التفاعل، والجدول (6) يبين ذلك: جدول (6) تحليل التباين الثلاثي (Three Way ANOVA) عديم التفاعل لدلالة الفروق في درجة توفر مهارات التفكير الناقد لدى معلمي اللغة العربية في مديريات التربية والتعليم في محافظة الكرك من وجهة نظرهم تبعا لمتغيرات (الجنس، المؤهل العلمي، سنوات الخبرة)

\begin{tabular}{|c|c|c|c|c|c|c|}
\hline مستوى الدلالة & قيمة (ف) & متوسط المربعات & درجة الحرية & مجموع المربعات & مصهدر التباين & المهارة \\
\hline .325 & .973 & .310 & 1 & .310 & الجنس & \multirow{6}{*}{ التحليل } \\
\hline .025 & 5.116 & 1.630 & 1 & 1.630 & المؤهل & \\
\hline \multirow[t]{4}{*}{.002} & 6.520 & 2.078 & 2 & 4.156 & الخبرة & \\
\hline & & .319 & 188 & 59.919 & الخطأ & \\
\hline & & & 193 & 2648.370 & الكلي & \\
\hline & & & 192 & 65.800 & الكلي المصحح & \\
\hline .962 & .002 & .001 & 1 & .001 & الجنس & \multirow{6}{*}{ الاستقراء } \\
\hline .002 & 9.771 & 3.319 & 1 & 3.319 & المؤهل & \\
\hline \multirow[t]{4}{*}{.031} & 3.548 & 1.205 & 2 & 2.411 & الخبرة & \\
\hline & & .340 & 188 & 63.863 & الخطأ & \\
\hline & & & 193 & 1891.571 & الكلي & \\
\hline & & & 192 & 69.556 & الكلي المصحح & \\
\hline .322 & .987 & .222 & 1 & .222 & الجنس & \multirow{6}{*}{ التفسير } \\
\hline .037 & 4.418 & .995 & 1 & .995 & المؤهل & \\
\hline \multirow[t]{4}{*}{.007} & 5.086 & 1.145 & 2 & 2.291 & الخبرة & \\
\hline & & .225 & 188 & 42.334 & الخطأ & \\
\hline & & & 193 & 2671.453 & الكلي & \\
\hline & & & 192 & 45.722 & الكلي المصحح & \\
\hline .250 & 1.334 & .361 & 1 & .361 & الجنس & \multirow{6}{*}{ الاستنتاج } \\
\hline .015 & 5.969 & 1.617 & 1 & 1.617 & المؤهل & \\
\hline \multirow[t]{4}{*}{.003} & 6.133 & 1.661 & 2 & 3.322 & الخبرة & \\
\hline & & .271 & 188 & 50.922 & الخطأ & \\
\hline & & & 193 & 2738.620 & الكلي & \\
\hline & & & 192 & 56.000 & الكلي المصحح & \\
\hline .707 & .142 & .029 & 1 & .029 & الجنس & \multirow{6}{*}{ التقويم } \\
\hline .024 & 5.185 & 1.077 & 1 & 1.077 & المؤهل & \\
\hline \multirow[t]{4}{*}{.002} & 6.440 & 1.338 & 2 & 2.676 & الخبرة & \\
\hline & & .208 & 188 & 39.054 & الخطأ & \\
\hline & & & 193 & 1704.727 & الكلي & \\
\hline & & & 192 & 42.718 & الكلي المصحح & \\
\hline .373 & .797 & .144 & 1 & .144 & الجنس & الكلي \\
\hline
\end{tabular}


المجلة العربية للطوم ونشر الأبحاث ـ مجلة العلوم التريوية والنفسية ـ المجلد الخامس ـ العدد السابع والثلاثون ـ أكتوبر 2021م

\begin{tabular}{|c|c|c|c|c|c|c|}
\hline مستوى الدلالة & قيمة (ف) & متوسط المربعات & درجة الحرية & مجموع المربعات & مصددر التباين & المهارة \\
\hline .004 & 8.666 & 1.569 & 1 & 1.569 & المؤهل & \\
\hline \multirow[t]{4}{*}{.000} & 7.948 & 1.439 & 2 & 2.879 & الخبرة & \\
\hline & & .181 & 188 & 34.045 & الخطأ & \\
\hline & & & 193 & 2293.259 & الكلي & \\
\hline & & & 192 & 38.493 & الكلي المصحح & \\
\hline
\end{tabular}

يلاحظ من الجدول (6) عدم وجود فروق ذات دلالة احصائية عند مستوى الدلالة (مي0.05) في درجة

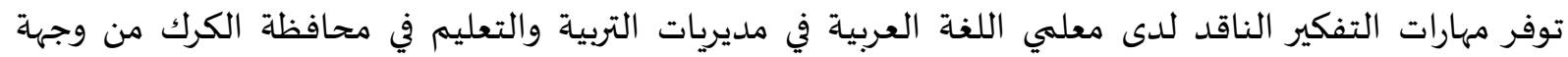

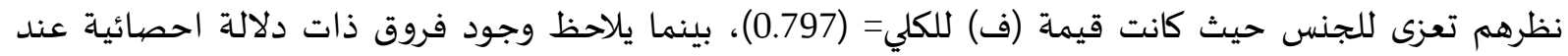
مستوى الدلالة (0.05) تعزى للمؤهل العلمي، حيث كانت قيمة (ف)= (8.66)، ولصالح المؤهل الاعلى (دراسات عليا)، كما يلاحظ وجود فروق ذات دلالة احصائية عند مستوى الدلالة (0.05 0 العزى لسنوات الخبرة، حيث كانت قيمة (ف)= (7.948)، ولتحديد اتجاه الفروق بالنسبة للخبرة تم استخدام اختبار شافيه للمقارنات البعدية

$$
\text { والجدول (7) يبين ذلك: }
$$

جدول (7) نتائج اختبار شافيه للمقارنات البعدية لاتجاه الفروق في درجة توفر مهارات التفكير الناقد لدى معلمي اللغة العربية في مديريات التربية والتعليم في محافظة الكرك من وجهة نظرهم تبعا للخبرة

\begin{tabular}{|c|c|c|c|c|}
\hline الدلالة & الفرق بين المتوسطين & الخبرة (ب) & الخبرة (أ) & المهارة \\
\hline .036 & $-.26126^{*}$ & 5- أقل من10سنوات & \multirow{2}{*}{ أقل من5سنوات } & \multirow{3}{*}{ التحليل } \\
\hline .004 & $-.35305^{*}$ & 10سنوات فاكثر & & \\
\hline .647 & -.09179 & 10سنوات فاكثثر & 5- أقل من10سنوات & \\
\hline .157 & -.20277 & 5- أقل من10سنوات & \multirow{2}{*}{ أقل من5سنوات } & \multirow{3}{*}{ الاستقراء } \\
\hline .047 & $-.27246^{*}$ & 10سنوات فأكثر & & \\
\hline .793 & -.06968 & 10سنوات فاكثثر & 5- أقل من10سنوات & \\
\hline .030 & $-.22588^{*}$ & 5- أقل من10سنوات & \multirow{2}{*}{ أقل من5سنوات } & \multirow{3}{*}{ التفسير } \\
\hline .024 & $-.24201^{*}$ & 10سنوات فأكثر & & \\
\hline .981 & -.01613 & 10سنوات فاكثثر & 5- أقل من10سنوات & \\
\hline .085 & -.20762 & 5- أقل من10سنوات & \multirow{2}{*}{ أقل من5سنوات } & \multirow{3}{*}{ الاستنتاج } \\
\hline .005 & $-.32111^{*}$ & 10سنوات فاكثثر & & \\
\hline .459 & -.11350 & 10سنوات فأكثر & 5- أقل من10سنوات & \\
\hline .283 & -.12908 & 5- أقل من10سنوات & \multirow{2}{*}{ أقل من5سنوات } & \multirow{3}{*}{ التقويم } \\
\hline .003 & $-.29251^{*}$ & 10سنوات فاكثر & & \\
\hline .121 & -.16343 & 10سنوات فأكثر & 5- أقل من10سنوات & \\
\hline .033 & $-.20177^{*}$ & 5- أقل من10سنوات & \multirow{2}{*}{ أقل من5سنوات } & \multirow{3}{*}{ الكلي الكلي } \\
\hline .001 & $-.29936^{*}$ & 10سنوات فاكثر & & \\
\hline .427 & -.09759 & 10سنوات فأكثر & 5- أقل من10سنوات & \\
\hline
\end{tabular}

يلاحظ من الجدول (7) أنَّ الفروق في درجة توفر مهارات التفكير الناقد لدى معلمي اللغة العربية في مديريات التربية والتعليم في محافظة الكرك من وجهة نظرهم تتمثل في الكلي ومهارتي (التحليل، والتفسير) بين من من منارئ

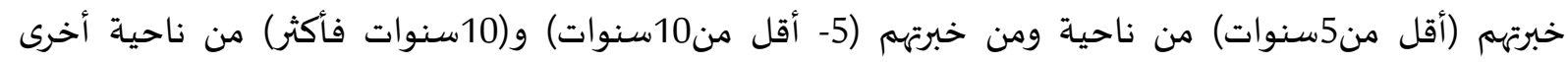

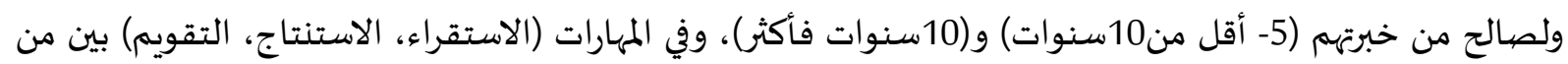


خبتهم (أقل من5سنوات) ومن خبتهم (10سنوات فأكثر) ولصالج من خبتههم (10سنوات فأكثر)؛ أي أن الفروق لصالح الخبرة الاعلى. وقد يعزى السبب في عدم وجود فروق في درجة توفر مهارات التفكير الناقد لدى معلمي اللغة العربية في

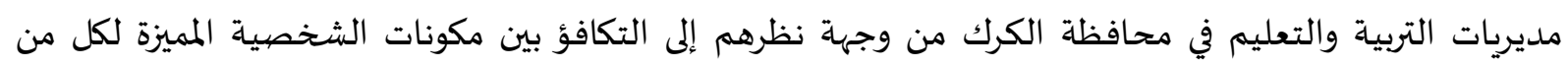

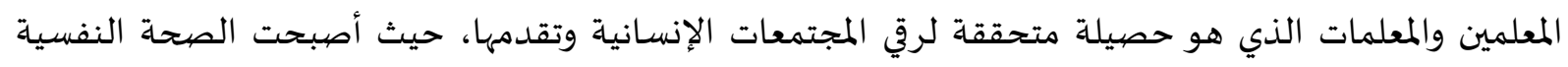

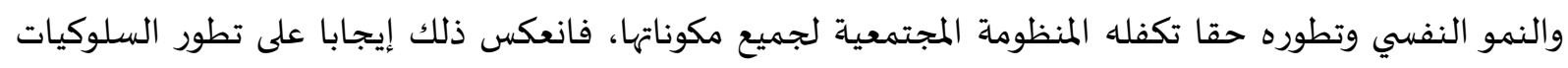

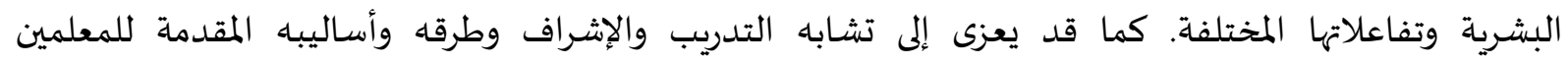

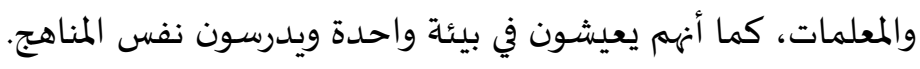

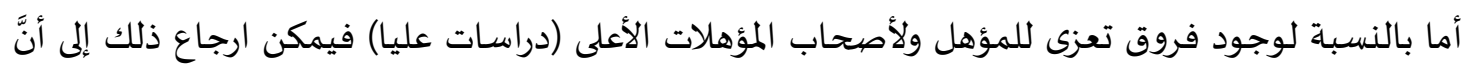
هؤلاء قد تلقوا أثناء دراساتهم في الماجستير والدكتوراه، ومن خلال اطلاعهم وأعمالهم البحثية، فكانوا أكثر اطلاعاً ومعرفة حول التفكير الناقد ومهاراته.

وفيما يتعلق بوجود فروق وجود فروق في درجة توفر مهارات التفكير الناقد لدى معلمي اللغة العربية في

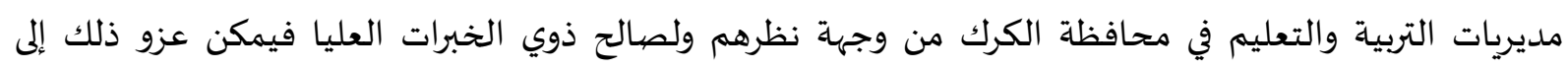

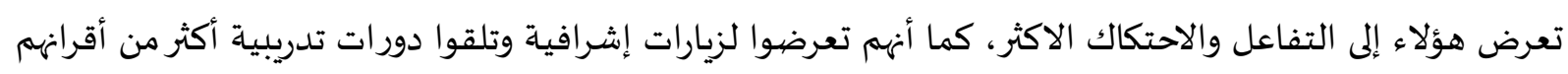
ذوي الخبرات القليلة.

\section{التوصيات والمقترحات.}

استناداً لما تم التوصل إليه من نتاتئج توصي الباحثة وتقترح الآتي:

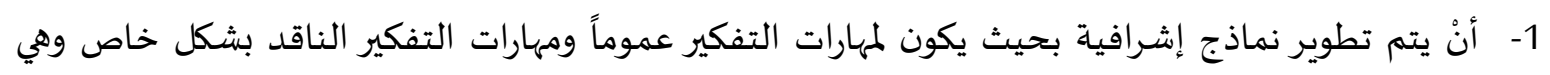

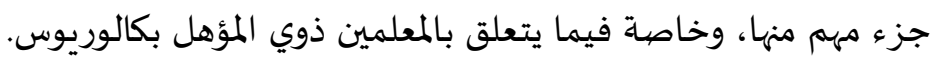

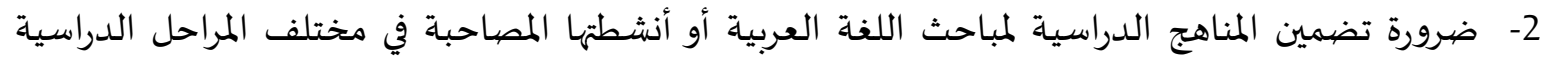
لمهارات التفكير الناقد. 3- تضمين البرامج التدرببية لإعداد المعلمين الجدد موضوعات تتعلق بتدربههم على استخدام أساليب التفكير الناقد واستراتيجياته في المواقف التعليمية. 4- تضمين المساقات الدراسية في كليات العلوم التربوية في الجامعات بكيفية تدريس التفكير الناقد.

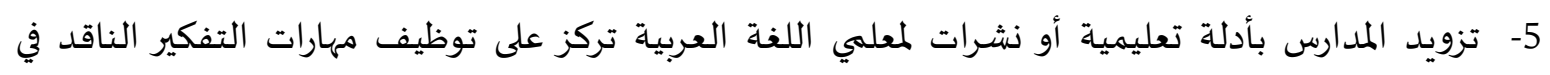
عملية التدريس. 6- ضرورة أنْ يراعى عند إعداد الأدوات والنماذج الإشرافية لتقييم أداء معلمي اللغة العربية، مدى توفر مهارات التفكير الناقد لديهم وممارستها واستخدامها أثناء عملية التدريس. 7- إجراء دراسة مشابهة على معلمين من تخصصيات أخرى، وعلى معلمي اللغة العربية في مناطق تعليمية أخرى. قائمة المراجع.

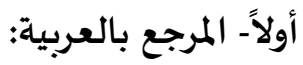
- إبراهيم، مجدي عزيز (2005). التفكير من منظور تربوي تعريفه طبيعته - مهارته - تنميته - أنماطه. القاهرة: عالم الكتب. 
- جروان، فتحي (2016). تعليم التفكير مفاهيم تطبيقات. الطبعة التاسعة، الأردن، عمان: دار الفكر ناشرون

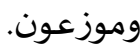
- ـ الحراحشة، إيمان (2015). درجة امتلاك معلمي العلوم للمرحلة الأساسية العليا لمهارات التفكير الناقد في المفرق. رسالة ماجستير غير منشورة، جامعة آل البيت: الأردن.

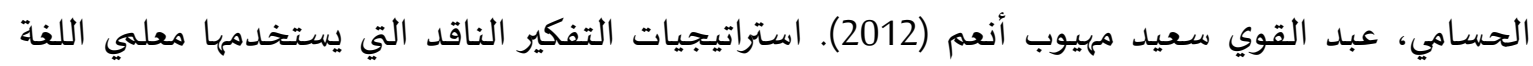
العربية في تدريس المفاهيم النحوية. حمادنة، أديب؛ والشواهين، سوزان (2017). درجة امتلاك معلمي اللغة العربية في المرحلة الاساسية العليا في

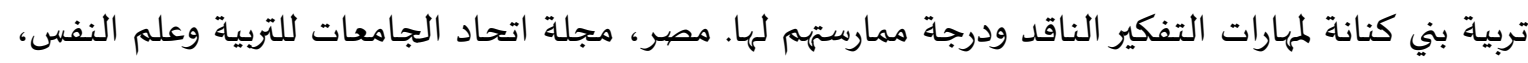
15 الحميري، عبد القادر (2018). درجة ممارسة معلمي العلوم لمهارات التفكير الناقد وعلاقته بمهارات التفكير العلمي والتحصيل لدى طلابهم في مقرر العلوم بالمرحلة المتوسطة. الأردن، مجلة دراسات، العلوم التربوية، 43 419-406: (4)

الربضي، مريم سالم (2004). أثر برنامج تدريبي قائم على مهارات التفكير الناقد في اكتساب معلمي الدراسات

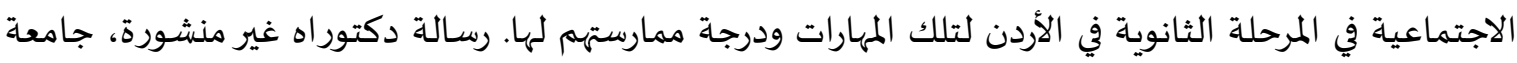
عمان العربية :عمان، الأردن. رزوقي، رعد؛ وعبد الكريم، سهى (2015). التفكير وأنماطه. الجزء الأول، الأردن، عمان: دار المسيرة للنشر والتوزيع

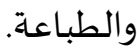
الزيادات، ماهر؛ والعوامرة، محمد (2009). مدى امتلاك معلمي مبحث التاريخ في مديرية تربية السلط لمهارات التفكير الناقد. مجلة المنارة للبحوث والدراسات بجامعة آل البيت، 15 (3): 181-202.

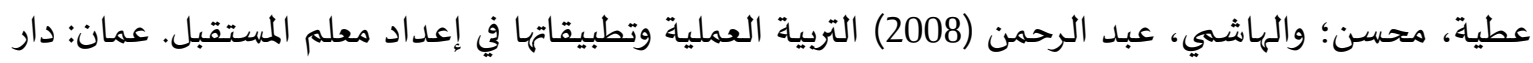
المناهج للنشر والتوزيع. الفقياه، محمد والكيلاني، احمد مجي (2014). درجة ممارسـة معلمي التربية الإسلامية في المرحلة الثانوية لمهارات التفكير الناقد وعلاقتها ببعض المتغيرات. حولية كلية الدراسات الإسلامية والعربية للبنات بالإسكندرية، 3 (33): .358-317

قطامي، نايفة (2004). تعليم التفكير للمرحلة الأسـاسية. الطبعة الثانية، الأردن، عمان: دار الفكر للطباعة والنشر والتوزيع.

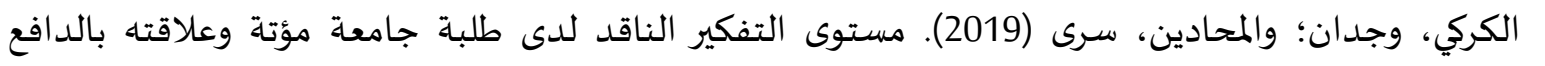

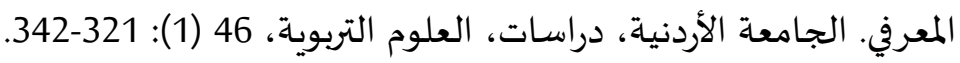
مرعي، توفيق ونوفل، محمد بكر (2007). مستوى مهارات التفكير الناقد لدى طلبة الدية كلية العلوم التربوية الجامعية (الأونروا). مجلة المنارة للبحوث والدراسـات، 13 (4): 289-341. النبهاني، سعود (2010). مستوى مهارات التفكير الناقد لدى طلبة كلية العلوم التطبيقية بنزوى في عمان. مجلة

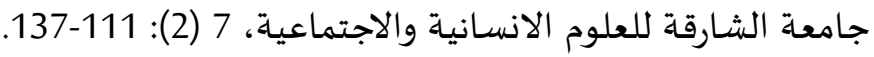
الهاشي، عبد الرحمن؛ والعزاوي، فائزة؛ والحلاق، علي (2010). درجة تمكن معلمي اللغة العبية في المرحلة

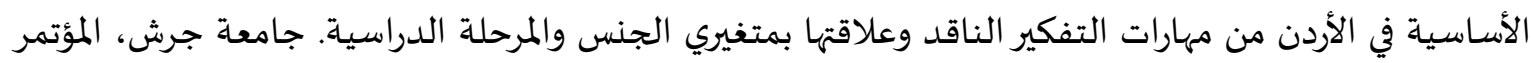
العلهي الثالث لكلية العلوم التربوية بجامعة جرش: مهارت تربية المعلم وتأهيله: رؤى معاصرة: 187-197. 
- الوادعي، شريفة (2017). أثر استخدام دورة التعلم الخماسي في تنمية مستوى مهارات التفكير الناقد في تدريس

المفاهيم النحوية في اللغة العربية لدى طالبات الصف الأول الثانوي. مجلة التربية بجامعة الأزهر، 1 (175):

\section{ثانياً - المراجع بالإنجليزية:}

- Akgun, A. \& Duruk, U. (2016). The Investigation of Preservice Science Teachers' Critical Thinking Dispositions in the Context of Personal and Social Factors. Science Education International, 27 (1): 3 15.

- Beyer, B. (1997). Improving student thinking: A comprehensive approach. Needham Heights, MA: Allyn \& Bacon.

- Christopher, B., (1998). Critical thinking Skills: An Interview with Dr. Richard Paul. ED 434227.

- Ennis, R. (1992). Critical thinking: What is it? Proceedings of the Forty-Eighth Annual Meeting of the Philosophy of Education Society Denver. Colorado, March 27-30.

- Facione, P. \& Facione, N. (2002). California Critical Thinking skills test. California Academic press. USA. from A, from B, from 2000 test Manual.

- Fisher, A. (2001). Critical Thinking: An Introduction. Cambridge University Press: United Kingdom.

- Frazier, D.M.\& west, E. (1997). Social studies in Secondary school.New York, Ronald Press Company.

- Halpern, D.F. (1998), Teaching Critical Thinking for Transfer Across Domains American Psychologist, 53 (4): 449-455.

- Kanik, F. (2010). An assessment of teachers' conceptions of critical thinking and practices for critical thinking development at seventh grade level. a thesis for the degree of Doctor of Philosophy, Middle East Technical University: Turkey

- Moore, B.N. \& parker, R. (2009). Critical Thinking, 9th ed, McGraw-Hill, New York, NY.

- Paule, P., Elder, L., \& Bartell, T. (1997). California Teacher Preparation for Instruction in Critical Thinking: Research Findings and Policy Recommendations. State of California, California Commission on Teacher Credentialing, Sacramento

- Watson, F. \& Glaser, E.M. (1980). Watson- Glaser Critical Thinking Appraisal. Dallas: Psychological Corporation. 